\title{
Barriers to Women's Career Advancement in the New Zealand Hospitality Industry
}

By Leah Macpherson.

A thesis submitted to Te Herenga Waka Victoria University of Wellington in partial fulfilment of the requirements for the degree of Master of Education 


\begin{abstract}
The glass ceiling effect is a widely researched phenomenon that highlights the multi-layered barriers to women's exclusion in senior management positions internationally. Traditionally, research has focused on evidence for the deficit in women's promotion in predominately corporate spheres with minimal inclusion of service sectors. The following research will address a key literature gap in the context of New Zealand, with an analysis of the glass ceiling barriers for career women in the hospitality industry. The qualitative study utilised a postmodern feminist lens and included 13 semi-structured interviews with current female duty managers in the localised Wellington, NZ region. The study found that the glass ceiling effect was maintained for female managers through the production of misogynistic cultures, genderstereotyping, and old boys' networks that functioned on intersectional levels. Obstacles were produced through customers, industry norms, and organisational practices that minimised participants ability to perform general operations, garner promotions, or access support in detrimental circumstances. The research concludes that women's professional development is hindered due to the interplay of workplace structures, broader socio-cultural beliefs, and resistance to female leadership. Based on the findings, recommendations for further emphasis on equitable and ethical industry practices are outlined to address the glass ceiling effect, thereby increasing employee investment and retention.
\end{abstract}




\section{Table of Contents}

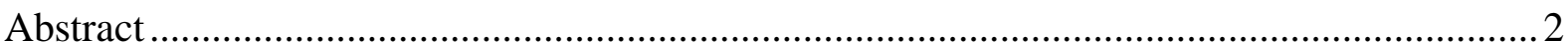

Chapter One: Introduction .............................................................................5

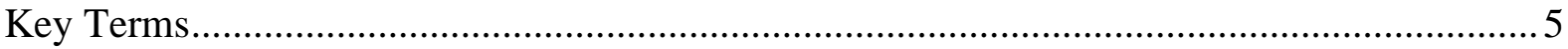

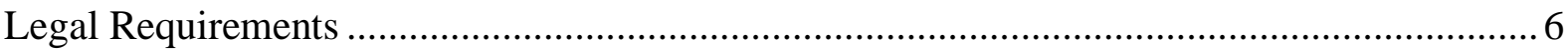

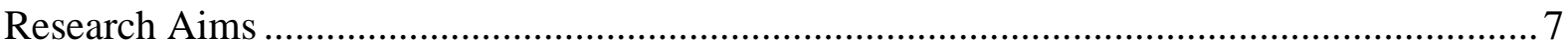

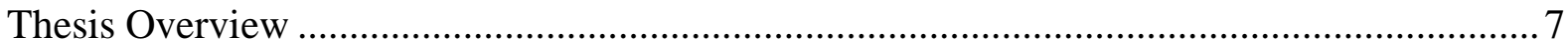

Chapter Two: Literature Review ..................................................................8

Glass Ceiling: Background Theoretical Perspectives ...................................................... 8

Deconstructing the Organisation: Culture in Practice ......................................................... 11

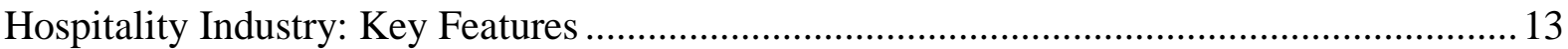

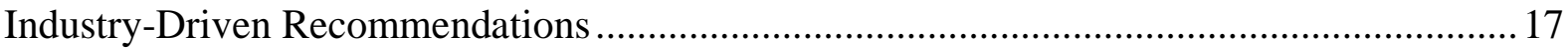

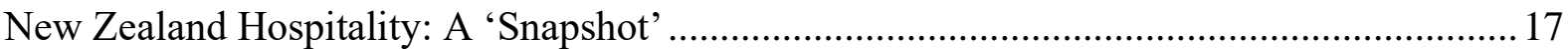

Chapter Three: Methodology .................................................................................. 19

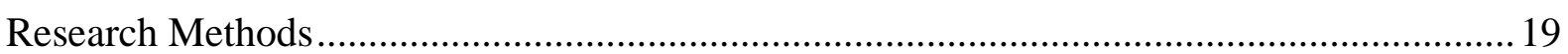

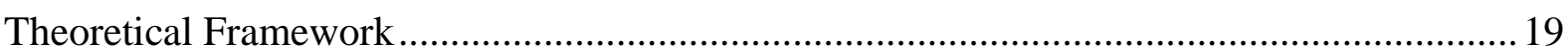

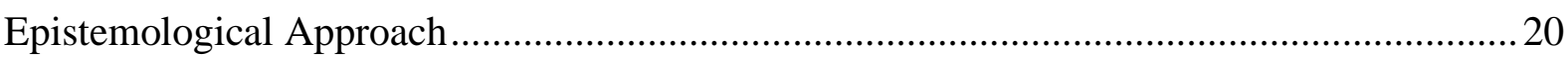

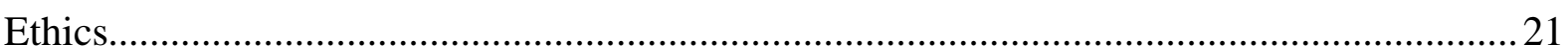

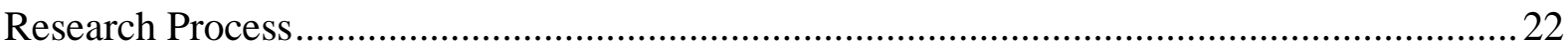

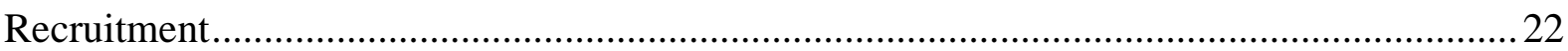

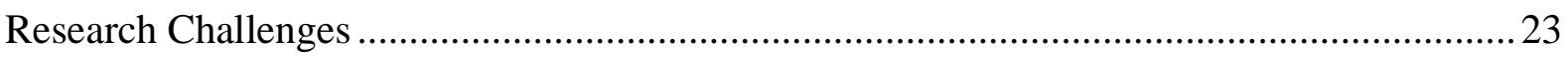

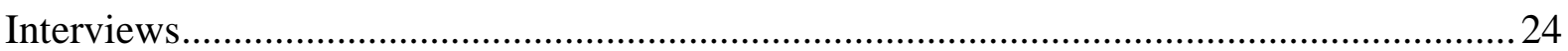

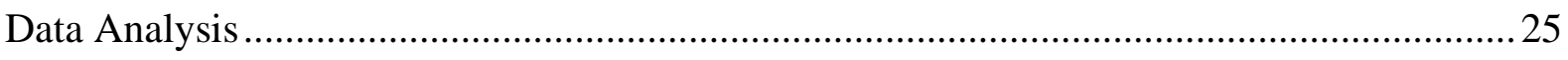

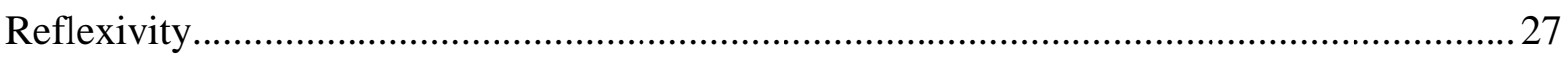

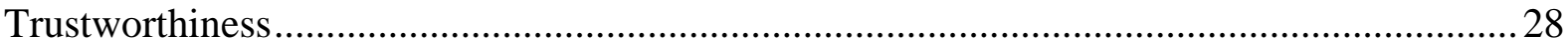

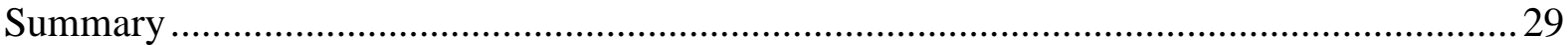

Chapter Four: Findings.................................................................. 30

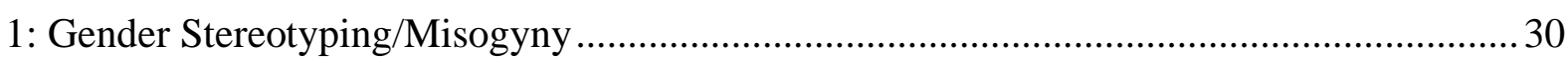

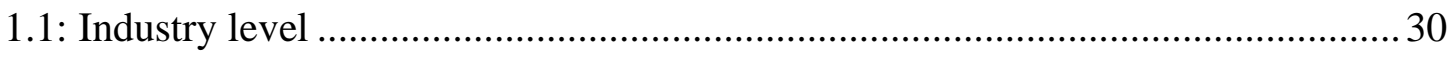

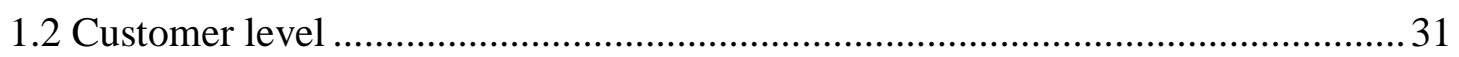

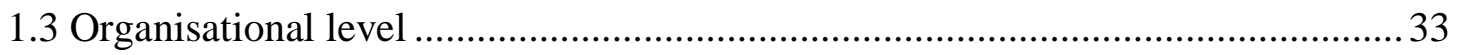

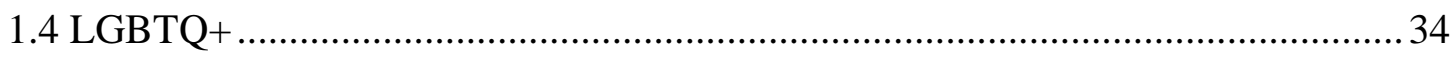

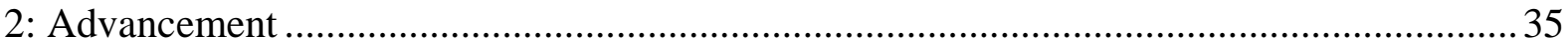




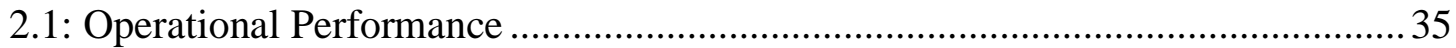

2.2 Promotional Access: A View from the Top of the Hierarchy ................................ 36

2.3 Sex-based Discrimination/Harassment ................................................................... 38

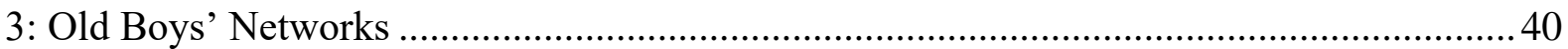

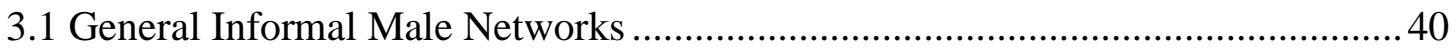

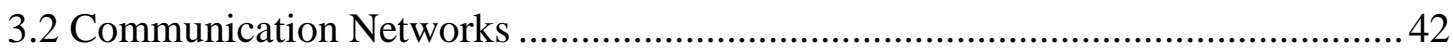

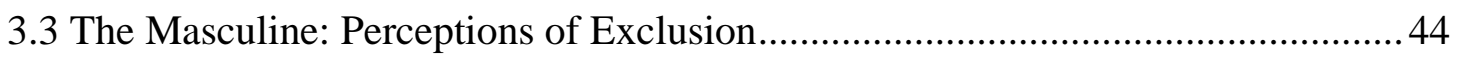

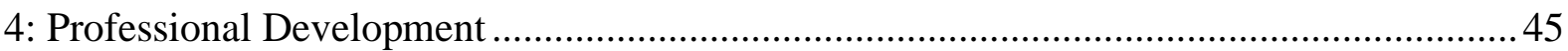

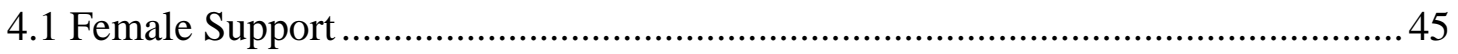

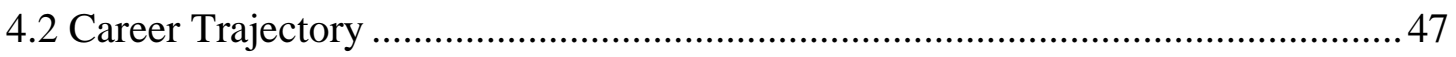

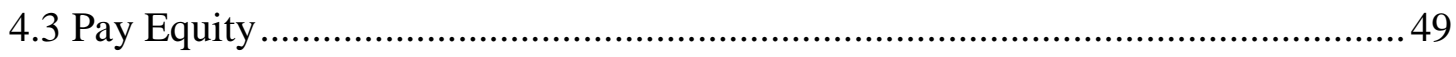

Chapter Five: Final Reflection ......................................................................551

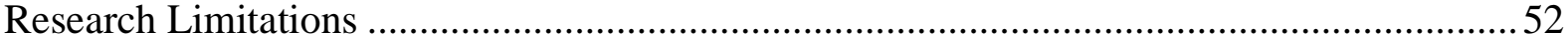

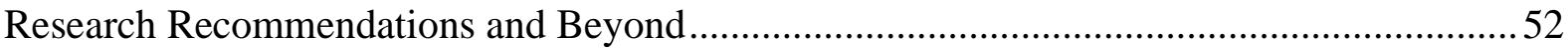

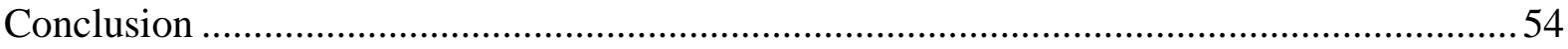

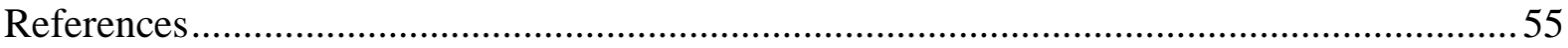

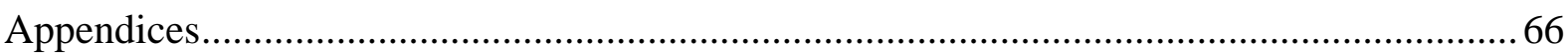




\section{Chapter 1: Introduction}

An umbrella term coined 'the glass ceiling' has been utilised as a metaphor for the relative obstacles to women's general advancement up the corporate ladder, and increased visibility in lower positions of the hierarchy (Altman, Simpson, Baruch \& Burke, 2005; Baumgarnter \& Schneider, 2010; Stelter, 2002). On an international scale, the majority of senior positions are dominated by the employment of male executives (Stelter, 2002; Weyer, 2007). Out of the global Fortune 500 companies in 2020, women obtained a mere $5.8 \%$ of CEO positions, and reached an average of $26.5 \%$ in overall senior/executive level management positions (Catalyst, 2020). This indicates that the higher echelons of the corporate ladder remain relatively inaccessible to career women globally (Catalyst, 2020; Oakley, 2000; Weyer, 2007).

Previous research has shown that even though the number of qualified women entering the global workforce has steadily increased from the second wave feminist influence in the 1980's, women's advancement into senior leadership has been limited (Townsend, 1997). International research has indicated the scale of the glass ceiling and its seemingly unified appearance in obstacles such as male networks, training/development, and hiring/promotional practices (Baumgarnter \& Schneider, 2010; Boone, et al., 2013). However, little research has been conducted for female managers employed in service sectors, such as the hospitality/tourism industry (Perez, et al., 2019). Within New Zealand, the hospitality industry accounts for the largest export earnings, and over half of gross domestic profit increasing yearly (Ministry of Business, 2020). As women are highly visible in lower positions of the service sector (Service IQ, 2020), the reason behind the noticeable absence of females at senior/executive levels is unclear.

This research aims to address the prominent gap in literature surrounding women's advancement in the hospitality industry with a focus on bar, café, and restaurant environments. This provided a contrast to limited previous research that is primarily centred on the feminisation of the hotel sector, in which gendered roles are increasingly pronounced (Mooney \& Ryan, 2009). Therefore, the study will provide the first qualitative inquiry into female duty manager's experiences of glass ceiling barriers in the context of NZ. To begin, the current chapter will outline the key terminology used in the theoretical underpinning of the thesis. This will be followed by the key research aims and brief overview of the thesis.

\section{Key Terms}

This research maintains a focus on the interplay of gender in the organisation through a postmodern feminist lens. Postmodern feminism is concerned with the interruption of patriarchal norms that generate gender inequalities, and the rejection of universal truths (Lather, 2007). With regard to this, postmodern feminism has contested biological arguments, by redefining gender as a social construction (Butler, 1988). Gender is viewed as a performance that is embodied through social interaction, and thus influenced by socio-cultural beliefs within the patriarchy (West \& Zimmerman, 1987). Therefore, the terms masculinity and femininity are associated with behaviours and practices attributed to men and women across social spheres (Guillaumin, 1985).

The dictation of masculinity/femininity can be seen as the modernisation of patriarchial power, wherein gender conformity is regulated according to social survelliance across all aspects in 
life (Bartky, 1997). Foucault (2000) theorises that survelliance is a discpline against the body enacted through authorative influences, with the regulation of social performances occuring throughout life in schooling, parenting, workplaces and government laws (Foucault, 2000). Taking this into account, the economic term 'neoliberalism' is adapted in the thesis to denote the societal emphasis placed on personal responsibility for individual success or failure (Larner, 2003), including the adaption to institutionalised gender expectations (Bartky, 1997). Neoliberalism fails to recognise the broader external conditions of which an individual faces intersectionally in life that contributes to their social position and polarisation (Larner, 2003). It is therefore used as a key term for understanding attitudes towards womens lack of advancement as a percieved self-imposed failure (Boone, et al., 2013). Furthermore, misogyny will be used in the thesis to describe the "hatred of, aversion to, or prejudice against women" (Merriam-Webster, 2021). Sexism will describe "prejudice or discrimination based on sex" (Merriam-Webster, 2021). The term 'intersectional oppressions' used in the thesis is defined as an "unjust or cruel exercise of authority or power...involving members of multiple social categories" (Merriam-Webster, 2021). These definitions will be applied to both the experiences of participants and findings of the study.

Male gender conformity is rewarded through the privileges of a patriarchal society as a source of power (West \& Zimmerman, 1987). Connell (2000) refers to the term 'hegemonic masculinity' as a cultural construction of gender that constitutes the pattern of practice allowing for womens continued subordination (Connell, 2000). The development of hegemonic masculinity is entirely dependant on the socio-cultural and structural dynamic of its environment, however in this thesis, it will refer to the prevailing masculine norm in the organisation, including compulsory heterosexuality and protection of male domination/privilege (Connell \& Messerschmidt, 2005). Therefore, the concept of gender construction will be used as the theoretical basis for discussion in this thesis.

\section{Legal Requirements}

This research will explore the experiences of female duty managers lack of advancement in the hospitality industry. Therefore, the legal process in attaining a licence and associated responsibilities should be underlined to inform the thesis. Firstly, a licence controller certificate (LCQ) must be obtained to ensure the individual has adequate understanding of the Sale and Supply of Alcohol Act (SSAA) (2012) that provides a strong guideline for practicioners to minimise alcohol related harm and be a responsible host. This can be completed online or in person through educational provider 'ServiceIQ' New Zealand.

Once the LCQ has been successfully completed, an individual who is 20 years old, with at least 6 months experience in the industry, can apply through the local council for their duty managers certification. After an successful interview with the council confirming licensing knowledge, the first application can be approved by the district licensing committee for 1 year, and subsequent renewals are over 3 yearly periods thereafter. Duty managers are expected to uphold the legal requirements of a licenced premise and act as individual practioners of the law. Therefore they have a significant responsibility to ensure the control of variables such as intoxication, aggressive/violent customers, health and safety requirements and current regulations (such as COVID-19 customer tracking). 
For context in this thesis, a 'general manager' (GM) is the highest ranked employee within the business hierarchy under the owner/s, who oversees all business operations- short and long term. A '2IC' is an employee second in charge to the GM. An 'operations manager' (OPS) is an employee who has a larger responsibility for admin, such as organising functions, rostering or accounts. All of these roles have varying responsibilities according to the business needs. All will need to retain a DM's licence.

\section{Research Aims}

The research aims to privilege the experiences of female duty managers currently employed in the NZ hospitality industry. To facilitate a greater depth of understanding, qualitative interviews were used to garner a detailed insight into potential barriers and intersectional oppressions faced by participants in their careers. The following research questions therefore arose:

- How are barriers to women's career advancement culturally constructed in the New Zealand hospitality industry?

- To what extent does the glass ceiling effect operate across organisations?

- How can the industry improve the working conditions and professional development for female duty managers in the industry?

The research will reflect on the limited literature that is focused on women's experience of glass ceiling barriers in the hospitality/tourism industry (Carvalho, et al., 2018; Clevenger \& Singh, 2013; Mooney \& Ryan, 2009; Perez, et al., 2019; Pizam, 2017). The relevant studies are limited in generalisability to the thesis however, due to their nearly exclusive focus on the hotel sector. Furthermore, existing research is primarily conducted outside of New Zealand, therefore incorporating different socio-economic conditions contributing to womens perception of glass ceiling effects. To address the existing literature gap, this investigation will provide the primary insight into the bar, restaurant and café division of the hospitality industry through employed women's experiences of barriers to their career development in the organisational hierarchy.

\section{Thesis Overview}

Chapter 1 outlines the research aims and background of the thesis. The following chapter 2 reviews existing literature relevant to the research, and contextualises the thesis in a broader context. Limited empirical research, centred on glass ceiling barriers in the service sector, has initally shifted the focus of the literature review to career obstacles experienced by women across global industries. These barriers will be discussed in conjunction with the role of gender in organisational hierarchies, corporate practices and broader structural/cultural issues influencing the appearance of the glass ceiling effect. Chapter 2 concludes with a discussion of limited empirical research within the context of the hospitality industry, and an examination of the characteristics pertaining to the NZ sector. Chapter 3 uncovers the epistemological approach, theoretical framework, research methods and initial research challenges. Chapter 4 explores the main findings of the thesis, divided into four sections according to themes. The first section discusses gender stereotyping and misogyny as influences on industry, customer and organisational levels with a comparison to LGBTQ+ venues. The second section discusses womens advancement in the context of their impeded operational performance, lack of promotional access, and experiences of sex-based 
discrimination/harrassment. The third section explores old boys' networks and influence on womens repression through lines of communication and general exclusion. The fourth section outlines a lack of professional development for women, and discusses peer-support, career trajectories and pay equity as areas that could stimulate better working conditions if improved. The thesis concludes in the final chapter 5 with a final reflection on the limitations of the research and reccomendations for the betterment of the NZ hospitality industry.

\section{Chapter Two: Literature Review}

Chapter 1 outlined the rationale behind the research and provided background knowledge of both social theory and legal process for advancement. Due to limited existing literature based in the hospitality industry, chapter 2 places the research in a broader context of literature to review the international glass ceiling effect. The review is initiated by providing a comprehensive background to the role of gender in the organisation, and will follow with an exploration of corporate practices, socio-cultural influences and structural barriers. Following this, an intersectional inquiry of limited empirical research is outlined in the context of the hospitality industry. The chapter concludes by examining the nuances of oppression against specific industry characteristics, background to the NZ context, and previous recommendations for better practice.

\section{Glass Ceiling: Background Theoretical Perspectives}

Organisations allow for critical gendering processes which can be interpreted as informal policies or practices that generate inequalities and effect male and female employees differently (Hearn, 2000). These everyday interactions on surface level seem to be gender neutral (such as hiring/promotion, networking events) but are performed in a way that creates differentiating patterns of submission and domination (Hearn, 2000). There are a multitude of theories stemming from the way these actions are performed in the corporate sphere which are grounded in different biological, social, structural and cultural explanations of gender identity and interaction (Lueptow, Garovich-Szabo, \& Lupetow, 2001). These theories highlight critical perspectives as to the construction of gender and its interplay with organisations.

\section{Biological Theory: Sex-Differences}

Biological theories state that gender stems from stable physical differences that influence social attitudes and behaviours (Eagly, Wood, \& Johannesen-Schmidt, 2004). These theories attribute women's lack of progression in the workforce to culturally feminised practices such as the prioritisation of domestic care (Eagly \& Karau, 2002; Eagly \& Wood, 2004). Social expectation theory is a biological explanation that highlights sex-stereotyping within the division of labour as the differences between masculine/feminine physical characteristics and associated roles (Eagly, Wood, \& Johannesen-Schmidt, 2004). An example is the dictation of women's reproduction systems deeming them predominantly responsible for domestic/maternal positions both at home and in professional life (Eagly \& Karau, 2002). In the workforce this has been acknowledged in the abundance of women occupying low level, personable human resource or receptionist positions (Baumgarnter \& Schneider, 2010). Therefore, females are theorised as relatively disadvantaged due to their traditional placement in the domestic sphere, with men befitting the historic position as the breadwinner due to physical suitability (Eagly \& Karau, 2002). 
The advantages then given to males in the gender/organisational hierarchy encompass not only beliefs about physical characteristics, but also involve generalised beliefs regarding cognitive ability, leadership skills and emotional dispositions (Eagly, Wood, \& Johannesen-Schmidt, 2004). These beliefs are transferrable across organisational boundaries and general daily life, on the premise that individuals judge others according to their level of conformity to feminine (communal) and masculine (agentic) characteristics (Eagly, Wood, \& Johannesen-Schmidt, 2004; Hoffman \& Hurst, 1990). Communal attributes are caring for others, inter-dependency, kindness and collaboration. Agentic attributes are leadership, assertiveness, competitiveness, and strength. Hoffman and Hurst (1990) found in an empirical study that focus groups perceived women as more suitable to domestic roles due to communal attributes, and associated men with agentic characteristics suited to professional work.

Although social expectation theory can account for influences on attitudes, its grounding in biological theory is archaic in the notion that physical differences can be responsible for social processes. Early feminist rhetoric has transcended the idea that identity construction is stagnant, with sex and gender differentiated as inequivalent terms (Butler, 1986). Conceptions of gender are borne from ingrained socialisation processes instead, wherein one's identity is produced from a stylised repetition of acts (Butler, 1986; 1988). Feminist theory is critical of 'natural' views of sex as an explanation as to why women are disadvantaged solely because of their physiology (Butler, 1988). Therefore in all contexts, it is imperative to be mindful of what social and cultural processes are directed against the male/feminine body that produce different meanings (Guillaumin, 1985). Social expectation theory has relevance in regard to gendered socialisation processes that affect individual judgements, yet is mistaken for its theoretical basis of the corporeal as a self-defeating prophecy on behalf of women.

\section{Social Theory: Embodying Gender}

\section{Masculinity}

For male dominance to operate unquestioned in social/professional settings, it needs continuous confirmation and repetition in its performance (Connell, 2001). Feminist rhetoric underlines the repeated cultural assertion of masculine characteristics as performances of leadership, dominance and power, the cultivation of 'naturally' occurring masculinity (Connell, 2000). This stems from socialisation practices in childhood where solidarity, comradery, maximising individual space, and corporeal autonomy are rewarded when performed in conjunction with gendered expectations (Butler, 1988; Guillaumin, 1985). Previous empirical research has substantiated the finding that individuals are rewarded for acting in a gender-consistent manner (Berger, et al., 1980; Cotes \& Feldman, 1996; Heilman, et al., 1989). Gender theory therefore emphasises the body as an active phenomenon wherein cultural or social ideologies are embodied, and thereafter confirmed and rejected by society (Butler, 1988).

There is an ideological overemphasis on masculinity as a normalised way of 'seeing', where male values are privileged as repeated assertions of social definition and control (Guillaumin, 1985). Masculinity is created through institutions such as schooling, the army, government, and workplaces to sustain a hierarchical structure through relentless surveillance of gendered norms (Connell, 2000; 2001; Foucault, 2000). These patterns of masculinisation encompass institutional arrangements such as authority/survelliance of conformity from figures such as 
parents, teachers and bosses, compulsory heterosexuality and gendered symbolisation through dress, language and behaviour (Connell \& Messerschmidt, 2005). For the current study, the socialisation of males in institutions becomes pertinent in reflecting upon the dictonomous relationship of gender in society and its construction in opposition to femininty.

\section{Femininity}

In contrast, from youth the female body is heavily regulated as an item of sexual value in western society, expressed through cultural stereotypes such as white, promiscuous and petite (Bartky, 1997). The 'male gaze', a term coined by Mulvey (1975) reflects on the patriarchal unconscious that dictates women's value dependant on their adherence to the mainstream sexualised image of femininity (Mulvey, 1975). Women's sexuality therefore is not necessarily empowering but can be a source of repression (Gavey, 2012). The feminine body is prescribed an inferior status and consistently judged as deficient against contemporary standards of femininity (Foucault, 1978). Women must conform to this cultural ideology of appearances whilst maintaining attributes such as approachability, cooperation and kindness (Eagly \& Karau, 2002). This is highly visible in leadership positions where there is immense emphasis on the balance of appearance and behaviour (Collinson \& Hearn, 2005). Women are placed in oppositional discourse to men and must be personally responsible for gender confirmation and rejection (Butler, 1988). This was confirmed in Wahl's (1998) empirical study of female managers, wherein participants expressed an internal conflict between professionalism and enacting femininity using language, appearance, and social behaviours (Wahl, 1998).

Female managers enact more interpersonal or communal behaviours when working with others, whilst males focus on task-orientation and individual gain (Bartol \& Martin, 1986; Bartol, Martin, \& Kromlowski, 2003). Cross and Madson's (1997) research found in interviews of female managers that a woman's self-concept in the organisation is based on the need for approval from others. A body of previous research has further substantiated this evidence in discovering that women's leadership performances were centred on interpersonal behaviours, with particular concern for subordinates (Adams, 1978; Camden \& Witt, 1983; Carless, 1998; Bartol, et al., 2003). These 'feminised' leadership skillsets have been found to be extremely successful for the development of lower-level female employees, who recognise female executives as more accessible and emotionally supportive, especially reflective in mentoring dyads (Leck, Elliott, \& Rockwell, 2012; Headlam-Wells, et al., 2006). Therefore in context, female managers display the qualities of transformational leadership inspired by participation, inspiration and collective innovation (Carless, 1998). In comparison, men rely on hierarchical relationships and define themselves in opposition to others (Connell, 2000; Connell \& Messerschmidt, 2005).

\section{Social-Biological Theories: Conclusion}

In an organisational setting it is evident that social expectation theory, and various studies on gender-based leadership can explain the basics of socio-cultural perceptions of men and women. However, social expectation theory is limited in scope with its continued reliance on the basic evolution of biology, and historical notion of reproductive tools as the basis of gender differences. Through a feminist lens it is evident that the production of gender is a performance, 
produced by socialisation practices dependant on culture, organisational practices, and leadership behaviours (Butler, 1988). Furthermore, it is extremely limiting to stereotype men and women in their capacity for leadership based on perceptions of masculine/feminine characteristics, which in itself acts as a barrier to analysis through the lens of equality (Perez, et al., 2019). Research has concluded that there are few differences in the capacity for leadership between men and women (Bartol, 1978), however, gender in leadership can have differentiating constructs of meaning across organisations, influencing the way in which practice is thought about and enacted according to the individual (Wahl, 1998; 2011). In Oakley's (2000) analysis of the glass ceiling effect, it is underlined that a feminist intersectional approach is necessary to incorporate an examination of the broader socio-cultural influences on leadership/gender performances.

\section{Deconstructing the Organisation: Culture in Practice}

An organisation consists of multiple persisting structures that develop detrimental cultures and gender-bias, thus contributing to the appearance of the glass ceiling (Meyerson \& Fletcher, 2000). In the previous section of this review, the dynamic between sex-expectations, masculine leadership norms and feminisation of interpersonal skills has been discussed in conjunction with the organisation (Eagly, Wood, \& Johannesen-Schmidt, 2004). This current segment of the review will incorporate the previously discussed social theory in conjunction with broader structural/cultural aspects of workplace environments. This is in alignment with Oakley's (2000) feminist analysis to ensure the examination of relevant literature maintains an intersectional approach in exploring elements of the glass ceiling.

The predominant components of the glass ceiling reside in corporate practices that develop both detrimental cultures and persist within the structure of the organisation. The predominant factors influencing women's exclusion from the executive sphere have been synthesised into three main categories:

1) The 'old boys' network;

2) The deficit in women's work/life balance; and

3) The deficit in women's professional development.

These components are non-stationary due to situational and cultural differences in organisations, however are focal points in deconstructing the glass ceiling across a plethora of previous research (Amaratunga et al., 2006; Bartol et al., 2003; Baumgarnter \& Schneider, 2010; Carvalho et al., 2018; Mooney \& Ryan, 2009). These categories will be discussed according to coporate practices, but are influenced by the structure of the organisation, of which is varied according to employee distribution, gendered task segregation and level of male power in the hierarchy (Wahl, 1992; 2001).

\section{Old Boy's Network}

Globally men hold more centralised and important positions on the corporate ladder (Catalyst, 2020). The 'old boy's' network reflects the maintenance of male dominance through exclusive access to critical decisions, projects, valuable information, job openings and promotions using informal networking advantages (Baumgartner \& Schneider, 2010; Elacqua, et al., 2009). Ragins, Townsend and Mattis (1998) found in a survey of 461 female executives, and 325 female CEO's of global fortune 500 companies that informal male networks were ranked as 
one of the most pervasive barriers to women's advancement. Women had to undertake a personal responsibility to obtain high profile assignments or challenges for the appearance of success, whereas old boy's networks delegated workplace opportunities automatically to men.

Further longitudinal empirical research has identified that over an 8 year period, males maintained a significant negative attitude towards female executives despite changing discourse around gender equality with the introduction of second wave feminism in the late 1970's (Dubno, 1985). It is evident that these findings are an indication of the current attitudes in the global market demonstrated by statistical evidence (Catalyst, 2020). This was supported by Wahl's (2014) international study of male networking in management teams, as men in interviews described female executives as inferior, even if they had obtained a superior position. Localised empirical evidence from Australia/New Zealand has identified that old boy's networks in transnational hotel management were also active outside of the organisation, including recreational activities such as exclusive events and after work drinks (Mooney \& Ryan, 2009). These events were identified as crucial times for the sharing of information or opportunities for the men in attendance (Mooney \& Ryan, 2009). Old boy's networks are therefore reproduced in organisational discourse to resist the perceived 'threat' of women (Oakley, 2000) and potential interruptions to power privileges (Pleasants, 2011).

\section{Work/life balance}

Stereotypical beliefs concreting a woman's place in domestic responsibilities can hinder an organisations support in hiring/retaining female employees (Baumgarnter \& Schneider, 2010). This lack of support has been shown to disadvantage the employee by affecting decisionmaking surrounding family and work, often resulting in women having to choose between the two (Baumgarnter \& Schneider, 2010). Women are regarded as primarily mothers and do not fit the image of an ideal worker, which generates discriminatory promotional practices (Acker, 1990). This has been supported by previous empirical research wherein female employees who had dependants were judged to be unavailable for promotions due to their perceived lack of geographical mobility (McIntosh, et al., 2012; Mooney \& Ryan, 2009). In turn, these same studies uncovered that female employees with children achieved higher levels of a work/life balance due to the hyperawareness of possible discrimination, of which did not have the same impact on men (Mooney \& Ryan, 2009; McIntosh, et al., 2012). Researchers Elacqua et al., (2009) in an empirical study found that employed women without children were considered immobile due to the possibility they might become pregnant and leave, and therefore unsuitable for promotion.

A New Zealand study found that women in the top 10 positions of the workforce were all unique in their personal choices regarding work and family life, underlining the risk of generalising females according to maternal stereotypes (Gautier, 2002). However, there is a small body of literature that reduces the glass ceiling to one that is a self-imposed issue, concluding that a womans choice between her personal and professional life is of her own volition, although reinforced by discriminatory workplace cultures (Boone, et al., 2013; Brizendine, 2008; Fischlmayr, 2002; Nelson, 2014; Soufi, Gilaninia, \& Mousavian, 2011). These studies enforce a contemporary understanding of the neoliberalist agenda, wherein the organisational responsibility for equitable promotional strategies and professional development is placed on the individual (Larner, 2003). Feminist research rejects this ideology, as broad persisting socio-cultural and structural issues occuring within the organisation are not 
problematised as contributors to the position of the female minority (Hesse-Biber, 2010). It has been found that men reify complicity to women's minority position in prioritising work over family life, due to the socially ingrained position of female partners as domestic carers (Hearn et al., 2008; Wahl, 2014). Men do not undergo discrimination when starting a family, and therefore have a heightened ability to retain a favourable position in the organisational hierarchy (Wahl, 2011).

\section{Professional Development/Mentorship}

Higher levels of social support through training incentives and professional development correlate to greater perceived job satisfaction and commitment from employees (Marcinkus, Whelan-Berry, \& Gordon, 2007). This is particularly salient for women in the organisation, as previous research has found that socio-emotional support was ranked by employed females as the most important feature of professional development schemes and mentoring relationships (Headlam-Wells, et al., 2006; Leck, et al., 2012; Turban, Dougherty, \& Lee, 2002). However, previous studies have shown that females access to guidance from senior executives, professional support and training opportunities are restricted across industries (Dainty, Neale \& Bagihole, 2000; Raabe \& Beehr, 2003). With less females in higher ranking positions, women seeking mentorship or development training to advance has proven to be difficult due to the dominance of male networks (Ragins, et al., 1998). Without adequate professional development, women are less competitive for promotions and job opportunities on the market, regardless of their relative education/qualifications (Dainty, Neale \& Bagihole, 2000). Businesses may appoint female employees in lower level positions such as communications or human resources, further neglecting to provide consistent training due to the nature of the position (Amaratunga, et al., 2006).

Researchers Allen, et al., (2004) have made clear that the benefits of mentoring may influence the way women are percieved in an organisation and simultaneously their own perceptions of success. Women who had experienced mentoring had a greater chance of promotion. In particular, female mentoring has been revealed as the most successful form of development for female mentees due to the generation of empowerment, confidence and gendered organisational navigation skills (Ehrich, 2008; Headlam-Wells, Gosland, \& Craig, 2005). Mentoring should not be generalised as the solution to the glass ceiling, as it is dependant on the success of the relationship, dominant informal networks, same-sex pairing and general accessibility to colleagues (Elacqua, et al., 2009). However it has been underlined that forming a mentoring relationship with direct supervisors lessens the exclusionatory effects of male networks, as mentees feel as though they are increasingly privy to information and opportunities in the working relationship (Elacqua, et al., 2009). The general problem that has been underlined in organisations however, is the general lack of formalised training or feedback on employee development, of which maintains the appearance of the glass ceiling (Bartram, 2005).

\section{Hospitality Industry: Key Features}

The first section of the review explored social/biological theories pertaining to gender and how it is organised in workplace environments. The previous section has deconstructed the glass ceiling in the context of organisational cultures and corporate practices that contribute to broader structural oppressions across industries. The following discussion will contextualise 
the broad dynamic of intersectional barriers that have been explored through previous research in the corporate world.

\section{Industry in Context}

Firstly, career obstacles for women in the hospitality/tourism industry are unique due to the characterisation of the work itself. Hospitality is viewed as a relatively unskilled industry reflected in low wages, shift work/long hours, low-grade employee opportunities compared to other sectors and low job security (Dowling, 2003; Lacher \& Oh, 2012). There is a notable lack of research to the lesser visibility of females in leadership roles within the private sector of hospitality (Carvalho, et al., 2018; Boone, et al., 2013; Lacher \& Oh, 2012; Mooney \& Ryan, 2009). Wahl (1992) concluded that research still grounded in neoliberalist perspectives are causing a failure to acknowledge a wider set of conditions that contribute to the structure and above characteristics of the hospitality sector in its highly gendered environment. This apparent research gap is furthermore significant due to the international importance and contribution that the tourism/hospitality industry has for the global economy (Lacher \& Oh, 2012).

The hospitality workforce is viewed to be participating in a 'lifestyle' choice, rather than a long-term career in which part-time or casual work is transitionary to the wider employment market (Dowling, 2003). This notion should be problematised, as the assumption that employees are not necessarily in pursuit of further development or training creates a lack of investment in its stakeholders (Dowling, 2003). Workplaces are highly gendered with roles such as waitressing, cleaning, receptionist, and human resource positions dominated by women (Pizam, 2017). This is a visible reflection of the vertical segregation of male and female employees who rarely hold identical positions in the industry (Perez, et al., 2019). Hospitality is therefore highly feminised, with a higher participation rate of women than men, but characterised as masculine in management positions in the concentration of male leadership at the top tier (Perez, et al., 2019). These gender structures help to reproduce and maintain the differences between females and males in role hierarchies, with males at the top of the chain of resources accentuating the appearance of a wage gap, differences in job responsibilities according to gender, contractual differences and so forth (Perez, et al., 2019; Pizam, 2017). In OECD countries, the median wage gap stands at $13.4 \%$, and increases with age (Catalyst, 2020).

The responsibility for professional development is transferred from the organisation to the individual as employees are expected to show versatility over many areas as evidence of mobility and competence (Mooney \& Ryan, 2009). This can be a huge barrier for women's career advancement due to the categorisation of women as preferable in lower positions of employment with low vocational mobility (Carbey, et al., 2003; Purcell, 1997). Therefore research suggests that men may appear more active within the hierarchy and foster solidarity in the top echelons of an organisation, whereas women must identify different areas in which they can draw success from in order to modify their positions: not only within workplace structure but associated gendered cultures (Broadbridge \& Hearn, 2008; Mooney \& Ryan, 2009). Having mobility and flexibility has traditionally only privileged senior management positions, with the nature of the industry meaning any work from home is made impossible, thus there is immense pressure to minimise personal time in favour of organisation (Boone, et al., 2013; Mooney \& Ryan, 2009). 
It is suggested that the nature of hospitality itself therefore actively deters women's participation in management as to be successful, personal life must be forfeited, the industry requiring such a lifestyle choice as a 'necessary evil' (Knutson \& Schmidgall, 1999; Maxwell, 1997). Studies have indicated that those female managers who have broken the glass ceiling are either single (without dependants) or divorced (Boone, et al., 2013; Carvalho, et al., 2018; Maxwell, 1997). This may be due both long hours cultures and the expectation of women to work harder for their own credibility whereas men automatically assume it (Acker, 1990; Wahl, 2014). Therefore the larger participation of women in the lower areas of the hierarchy are seen as 'tokens' of gender equality but are unreflective of larger persisting male dominated structures (Benschop \& Doorewaard, 1998). Thus, gender inequalities persist despite appearance of women's participation (Benschop \& Doorewaard, 1998).

\section{Visibility vs. Invisibility}

Women are therefore immediately visible in the industry in their occupation of front-facing customer service roles. The minimisation of women in these positions has been problematised by Clevenger and Singh (2013) who found in a surveys of over 150 hospitality workers that $74 \%$ of respondents strongly agreed that there was an abundant supply of qualified female employees who were visibly not advancing in their respective careers. It was therefore suggested that diversity intiatives such as mentoring/training, and a comphrensive review of internal barriers to women's development should be implemented. Furthermore, Mooney and Ryan (2009) found that in the hotel management sector, 99\% of upper management were percieved to be male with a long history of established solidarity in teams. In interviews, male hoteliers expressed their expectations of general management positions to be filled by men, highlighting a strong resistance to womens ascendance in the hierarchy. The preference for men, connected with the male norm of leadership, create major practices of homosocial and marginalising behaviours in organisations (Broadbridge \& Hearn, 2008).

Women's lack of advancement from entry level positions is visible across the industry, however dichotomous invisible barriers exist at higher levels of the organisation which contribute to broader socio-cultural discourse to maintain the appearance of the glass ceiling (Carvalho, et al., 2018). Previous research has identified that females who have successfully gained promotion in advancing to managerial levels are still affected by subtle forms of discrimination that appear to linger even after the ceiling has been broken (Meyerson \& Fletcher, 2000). Researchers Carvalho, et al., (2018) found that women verbalised inequalities in the hospitality/tourism field with ease, yet denied any personal experience of gender-based discrimination, including a lack of credibility or visibility in the sector. This was seen as a reluctance to place a definitive label on discrimination, even though all female managers recognised its unfairness and operation against other women.

The avoidance of being a 'victim' to sex discrimination ensures its operation with low visibility in the industry (Kantola, 2008). Women actively avoid being labelled a victim often to minimise the mental/emotional harm that arises with confronting the circumstances (Crosby, 1984; Kantola, 2008). For example, Ng and Pine (2003) interviewed female hotel managers in Hong Kong, concluding that women downplayed gender-based discriminatory difficulties in favour of personal strategies rather than relying on the institution for equitable practices. It has also been shown that although female managers acknowledge gender-stereotyping and oppressive structures in organisational systems, some women explained a lack of female 
promotion with essentialist rhetoric: that is women/men being 'essentially' physically and mentally different, reflecting their relative advancement (Carvahlo, et al., 2018). This criticism from participants using essentialist discourse confirmed that gender prejudices/stereotypes (e.g. sex-roles, mothers) existed even between women, ingrained to such an extent in both socialisation and organisational processes that they were invisible to the women themselves.

In contrast, the acceptance of discriminatory practices without intervention or instigation by male collectives has been dubbed "complicit masculinity" (Connell, 2001). Complicit masculinity operates invisibly through men's relative uptake of the benefits associated with discriminatory promotional practices and misogynistic cultures that are invisibly supported through the reluctance to initiate change and maintainence of privileges. Participants of complicit masculinity may not enact the practices and actions of the dominant group, however reinforce male ascendance in workplace cultures through silence (Connell \& Messerschmidt, 2005). Complicit masculinity contributes to larger structural oppressions, with empirical research understanding men's negative reactions to gender equality initatives as a sense of comfortability in the status quo, and purposeful ignorance to problematic behaviours (Wahl, 2012 ; 2014). The possiblity for change has been found to reside in the actions of men within the organisation, as Wahl (2014) concluded that deviation from the management ideal is only possible from those in positions of power: thus rendering women furthermore invisible in their inability to disrupt prejudice.

\section{Sexuality}

The previous discussion has outlined a theoretical analysis for the way in which heterosexuality or the male gaze operates in the organisation as a source of oppression (Mulvey, 1975). In the context of the hospitality industry, sexual harrassment is a persistent problem, with the sector often characterised by the sexual exploitation of women (Hoel \& Einarsen, 2003; Yea, 2005). Women contend with the saturation of sexuality ingrained in broader sociocultural discourse in front of house/management positions that generate the perception of bodily availability to customers (Gavey, 2012). Due to the structural conditions of the patriarchy, women are faced with the tension between individual empowerment and disenfranchisement as a sexual subject due to the common occurrence of sexual violence at work (Carvalho, et al., 2018; Wijesinghe, 2017). Research conducted through interviews of employees in the restaurant/bar sector of Auckland, NZ, revealed that the age difference between employees and customers led to power imbalances which made it difficult for less experienced women in the industry to repel sexual harrassment (Waudby \& Poulston, 2017). This was supported statistically, as unwanted sexual advances and harrassment are experienced by one in four women in the industry (Poulston, 2008).

A study conducted by Carvalho et al., (2018) uncovered that the operation of male VIP networks were described by participants as power circles that in some instances, allowed them to rape/sexually assault lower level female employees without reprecussion. The study underlined that sexual advances made by men were common and occurred on both extreme and minor levels without consequence. These findings substantiated Hearn and Parkin's (2003) identification of the interrelation between sexuality, violence and the organisation as 'management cultures' that are responsible for the reproduction of broader structrual issues within the patriarchy. Brickell (2009) argued that sexuality itself redefines and constitutes power arrangements, however, could be negotiated according to prevailing social discourse. 
This is seen in the hospitality industry through the minimisation of women's agency in the hierarchy due to the normalisation of sexual violence as a source of repression (Yea, 2005). Sexuality in practice therefore stimulates power arrangements that results in the invisibility of men's collective actions and ensures their unquestioned operation against the female body (Collinson \& Hearn, 2005).

\section{Industry-Driven Recommendations}

The discussion of visible/invisible barriers, sexuality and power relations for women in the industry has provided an overview of the varied, intersectional ways in which broader structural/cultural issues are framed in the context of the hospitality organisation. This discussion will now review recommendations for changes in the industry internationally that have been suggested to provide guidance for the minimisation of glass ceiling effects (Acker, 2006; Esping-Andersen, 2005). This will inform the research in providing a review of the strategies and challenges outlined by academics to disrupt masculinised structures in current practice (Carvalho et al., 2018; Clevenger \& Singh, 2013; Ferguson, 2009; Perez et al., 2019).

Perez, et al., (2019) concluded that the main barriers for female managers were invisible on intersectional levels. On the individual level, women created barriers through negative selfperceptions that were generated by failed interactions with organisational opressions, such as the inaibility to balance work/personal life, and masculinised leadership styles. Due to the uninterrupted nature of detrimental corporate practice cross-organisationally, it was suggested that a global movement towards gender equality initiatives in the industry should be instigated to disrupt current discourse regarding the way work is performed. The researchers indicated that to reduce strain on family/personal life, a re-organisation of the way in which assignments are completed should be proposed through online technologies that could allow for admin related tasks to be completed at home. Ferguson (2009) suggested that equality policies would develop organisational accountability and help to promote and retain female employees. However, it was noted that initiatives must be a collaborative effort between academics and practitioners to ensure that the intersectional nature of the glass ceiling is addressed, and changes to practice are incorporated without stimulating further barriers.

Clevenger and Singh (2013) expanded on this notion in providing a detailed response to the enabling of organisational initatives in the hospitality environment. Their results concluded that overall, women are achieving a small amount of success whilst navigating the barriers of the glass ceiling, yet continued to be underrepresented in hospitality management. Firstly, it was recommended that there should be a restructuring of the old boys network to identify factors contributing to differential treatment, by focusing networking internally. Moreover, further recommendations included making promotion processes transparent in introducing diversity policies that include mentorship/further training, thus creating accountability on behalf of senior management. This would be completed by the creation of performance metrics that set clear responsibilites for workplace roles, so all employees could complete tasks to the same standards. Lastly, it was recommended that there should be an examination of preexisting assumptions in the organisation to develop unique diversity strategies according to business needs. These detailed recommendations provided insight for an industry level movement towards eliminating gender bias, by invigorating both awareness and accountability for intersectional oppressions. 


\section{New Zealand Hospitality: A Snapshot}

The review has contextualised the hospitality industry in broad international research through its general characterisation, demonstration of visible/invisible barriers for women, influence of sexuality and global recommendations for improvement. The previous section has constructed the basis of limited industry-specfic research and provided the background to issues experienced by female employees on a global scale. The following section will review current industry statistics to provide an understanding of their significance to the local economy and inform this thesis.

In the year ending February 2020, there were 133,100 employees working in the hospitality/tourism industry in New Zealand with more than 75,000 of these workers in restaurant/café environments (RANZ \& Statistics NZ, 2020). In the year ending March 2020, nationwide spending for the hospitality industry increased by $4.2 \%$ and boasted $\$ 11.7$ billion total spend (RANZ \& Statistics NZ, 2020). The highest growth of 5.1\% in the sector was in café, bars, and restaurants. The capital city of Wellington is the third largest employer in the sector with 16,100 recorded workers and has the highest national growth of $4.6 \%$ in overall industry. In the Wellington café, bar and restaurant sector, $51.1 \%$ of employees are female, and $51.8 \%$ of these employees are duty managers (Service IQ, 2020). This is compared to a national average of $56.6 \%$ of female employees in the same sector, with $56.8 \%$ of these operating as managers. Over $40 \%$ of employees in the sector are under 25 years of age of which is a unique characteristic compared to the rest of the national economy standing at $11 \%$. Statistical evidence for gender distribution in corporate ownership of bar/restaurant/cafes is unavailable.

There have been key issues in the recent financial year that have affected the industry and its employees. Firstly, there have been two minimum wage increases from April 2019 to \$17.70, and following April 2020 to $\$ 18.90$ (Employment NZ, 2020). Secondly, the COVID-19 pandemic has effected the industry through a loss in revenue and decreased spending. The largest impact is shown in the June quarter of the NZ lockdown period of which disproportionately affected women (Statistics NZ, 2020). Due to the enconomic impact of mandatory business closures to manage the health risk, 11,000 hospitality/retail industry workers lost their jobs, and 10,000 of these employees were women (Statistics NZ, 2020). The disproportionate impact COVID-19 has had on women's employment is significant and detrimental for future positive moments towards quality in hospitality organisations. The large scale redundancies occurred even though the government introduced a wage subsidy scheme that provided NZ businesses with financial support, which was distributed to employees weekly by employers between $10^{\text {th }}$ June and $1^{\text {st }}$ September to maintain employment connections (Employment NZ, 2020).

The issues pertaining to the glass ceiling effect have now been discussed in the context of both corporate cultures and the hospitality industry. However, the lack of research into the promotion and visibility of managers in the localised café/restaurant/bar sector may contribute to a potential deficit in its performance. To increase the development, diversification, expansion and invigoration of this industry, there must be continued investment into its stakeholders. Therefore, the research will explore the development of the sector, by examining socio-cultural barriers for women at the management level in organisational structures. 


\section{Chapter 3: Methodology}

This research aims to understand the gendered barriers to female advancement in the Wellington, New Zealand region. Chapter 2 provided an analysis on the broader existing literature surrounding glass ceiling barriers internationally, with insight into the characteristics of the hospitality industry and gendered processes occuring within organisations. Chapter 3, methodology, explains the epistemological approach and research proceedings with an adherence to feminist research methods. A reflexive discussion follows regarding the position of the researcher as a hospitality manager, and how trustworthiness and credibility were established.

\section{Research Methods}

The aim of the research was to explore how barriers to women's career advancement were culturally constructed in the New Zealand hospitality industry, and to what extent they operated across organisations. The research utilised a qualitative design to uncover a rich set of data that was reflective of subjective experiences across multiple realities (Braun \& Clarke, 2013). Traditionally, qualitative research is unconstrained to a particular method or discipline but rather aims to understand the complexities of lived experiences (Lee, 2012). For the current study, the most appropriate design was semi-structured interviews that were participant-led, because it allowed for exploratory questions and accomodated for unanticipated dialogue (Braun \& Clarke, 2013; Shaw, Dyson, \& Peel, 2008). Using this method, the research used a hollistic approach to prioritise the female voice, by conducting the research 'for', rather than 'on' the participant (Creswell, 2007). This was imperative in adopting a feminist qualitative methodology, to legitimise women's experiences and explore the interplay of gender in dialogical contructions (Shaw et al., 2008). The qualitative research design also ensured that the researcher had a certain level of involvement in the data collection process, with flexibility as to the direction of the interviews (Braun \& Clarke, 2013).

\section{Theoretical Framework}

The research utilises a postmodern feminist lens, which is primarily concerned with the promotion of womens' subjectivity against broader patriarchal norms (Butler, 1988). It acknowledges that womens oppression exists on intersectional levels and is experienced differently according to wider socio-cultural conditions (Lather, 2017). Postmodern feminism questions dominant methodological, epistemological and ontological paradigms by critically rethinking objectivity (Lather, 2007). Objectivity in this thesis is redefined to place the participant in a situated perspective, with their perceptions both partial and unique (Lather, 2007). The research utlises this theoretical lens in the recognition of the complexity of womens experiences, and rejects overarching social 'truths' or explanations (Gannon \& Davies, 2014). This is aligned with the traditional aim of qualitative research to understand the multiplicity of individual realities (Braun \& Clarke, 2013). 
A postmodern feminist lens will draw close attention to the establishment and maintanence of power dynamics expressed through participant dialogue (Davies, 2008). This will problematise cultural binaries that naturalise the appearance of inferiority, such as hierachical notions of men/women (Gannon \& Davies, 2014). The female voice will be emancipated from binaries through the validation of their experiences as individual agents, thereby repositioning participants outside of detrimental dichotomies (Davies, 2008). This will be performed by close attention to the composition of language and its effects to allow for women to reclaim their personal experiences seperated from a dominant narrative, thus empowering their reflections (Davies, et al., 2004; Lincoln \& Denzin, 2003).

Language, however, is also fundamentally constituted by socially produced power relations, and influenced how women explored experiences in reference to gender relations in the organisation (Kincheloe \& McLaren, 2005). This meant that further consideration of social positioning during data collection and analysis was imperative to uncover the way in which subjectification operated (Davies, 2008). Subjectification was reviewed as the production of power relations in which the subject and their experiences are socially produced as a constant process (Foucault, 2000). Participants were therefore given a platform wherein language became a tool to express their own agency, rather than reproducing ideologies present in existing partriarchal conditions (Butler, 1988; Davies, 2008). Feminist research recognises the importance of agency for women in conducting studies to eliminate inequalities, by focusing on social processes, language and interactions as forms of knowledge (Davies et al., 2004; Hesse-Biber, 2010).

\section{Epistemological Approach}

The theoretical perspective of postmodern feminism describes how knowledge in the current research is understood. The epistemological approach highlights how such knowledge is possible, to ensure its legitimacy and relevance to the research aims (Crotty, 1998). Positivist epistemology views reality as objective, where meaning can be discovered through varying research methods (Crotty, 1998). In contrast, constructivist epistomology views meaning as a social construction and rejects the notion that it can be objectively discovered, due to the multiplicity of forms meaning may have for different people (Crotty, 1998). This thesis adopted a constructivist epistomological approach, in the recognition that knowledge contains varied and complex perspectives (Leckenby, 2007). This approach will inform a multilayered and nuanced view of realities that are only made possible through interactions, in the acknowledgement that social phenomena do not occur organically (Hesse-Biber, 2010). This was significant for this research as epistemologically, feminist research aims to validate womens experiences as a source of knowledge, that should be reflected on critically to inform an understanding of the social world (Brown, Western, \& Pascal, 2013).

Feminist epistemologies seek to explore the diverse nature of females experience in society, (Hesse-Biber \& Leavy, 2007), thereby widening opportunities for the co-creation of both learning and knowledge, and to provoke a heightened awareness of the oppressions associated with minority social positions (Brown, Western, \& Pascal, 2013). This can also stimulate a change in perspective for participants for the way in which they understand interactions through life (Hesse-Biber \& Leavy, 2007). A point of difference in feminist research is the positionality of the researcher, as they are included through either their own personal interest or experience in the topic/environment (Stanely, 1990). This was particularly salient in this research due to 
my experience of over 5+ years in the hospitality industry as a female DM, meaning that any differences in power/status with my participants were minimised through my positionality in identical employment and indepth understanding of industry operations. Feminist researchers are reflexive, and due to my personal involvement in the research, it was possible to build higher levels of rapport and trust in a reciprocal relationship with my participants (Brown, Western, \& Pascal, 2013; Visweswaran, 1994). Feminist epistemological qualitative enquiry can therefore promote more authentic values, beliefs and story telling for rich and more accurate descriptions (Howe, 2004).

This approach aims to minimise research bias, by ensuring that the influence of the researcher does not serve to privilege the interests of those in power (Hesse-Biber \& Piatelli, 2014; Intemann, 2016). It is objective in the diversity of its inquiry and necessary social conciousness to ensure that negative bias was more likely to be identified and counteracted (Intemann, 2016). My authority as an investigating subject within a limited community of practice was reviewed against all potential participants before the qualitative research was performed, by verifying that participants held the same position or higher as myself to minimise power differences in interviews (Visweswaran, 1994). I also had to consider the naunces and similarities in my position, with 6 years managerial experience in all levels of a hospitality business: for example as a waitress, dishwasher, bartender, duty manager, second in charge and general manager. Because I have a high level of operational understanding in each position with similar experiences of misogyny, it became evident that I was able to adopt an insider status to broader oppressions in the industry alongside my participants (Hesse-Biber \& Leavy, 2007).

\section{Ethics}

The research was conducted with adherence to Victoria University of Wellington's Human Ethics and Guidelines Policy. An application for ethics approval was approved by the Victoria University of Wellington's Ethics Committee (\#0000027726) and was granted on the $21^{\text {st }}$ of February 2020. The committee raised some issues that were amended before approval was granted, including a change to the maximum age of my participants from 35 to 55 years of age to be less restrictive. However, due to the young demographic of the industry, my most experienced participant was 32 years old. Further changes were made, as the committee wanted clarification on how sensitive topics such as situational sexism and misogyny would be discussed without potentially harming the participant or making them uncomfortable. I ensured that the information shared in the interviews was treated with confidentiality and sensitivity by firstly obtaining informed consent before the research was conducted. This was through signed consent forms that outlined the interview process, what the participants could expect, how their information would be protected (through removing all identifying information in the research process), and how they were able to stop the interview at any time (see Appendix A). Before each interview was conducted, I verbally repeated this information for confirmation that all participants understood the forms. The participants also had the option of receiving a full transcript or summary of the interview, and a copy of the final report sent to a chosen email address. This was to create additional opportunity for all participants to read and comment on the level of identifiability in their interview summaries and either confirm or reject certain information that they may or may not feel comfortable with.

To protect their identities, participants were refered to by randomised numbers for anonymity. I removed certain aspects of personal information including business/staff names from shared 
experiences, and paid particular attention to sensitive situations of sexual assault or misogyny to generalise some identifable details. All participants had the option to withdraw from the study by April $1^{\text {st }} 2020$, and were notified of the possibility that the research could be used for publishing or presentation at conferences. The Ethics Committee were also concerned about how I would manage any prior professional or personal relationships with my participants. I made sure that all participants were in either in the same industry position or above as myself and applied the same rule to any potential relationships between the final group of participants. I acknowledged that my participants may have previous friendships or professional relationships with each other but ensured that their identities were not disclosed. They were, however, free to voluntarily discuss their participation with other members in the community, which resulted in an unintentional snowball effect in the initial recruitment stages and aided the outreach of the study.

All of the audio recorded data from interviews was stored on an encrypted voice recording application of which was promptly deleted after the completion of my interview transcripts. The interview transcripts were manually transcribed onto word documents then kept on a password-locked folder on my personal computer in my home-office.

\section{Research Process}

\section{Recruitment}

The research involved 20-30 minute semi-structured interviews with 13 women who had at least 1-2 years experience as a NZ qualified duty manager, and were currently working in the industry in this position or higher. The recruitment process initially took a purposive approach with the primary concern of achieving a representative sample of a multitude of businesses around the Wellington region. I aimed to recruit managers that were currently working at different venues, and did not work with each other directly to achieve a larger degree of crossorganisational seperation. The participants had to fit the criteria of an age range starting from 20 years of age, of which a duty manager's certification can be gained legally in New Zealand, up to 55 years of age. I primarily used social media advertising on the 'Wellington Bartender Exchange' Facebook page with 5400 members across the industry to reach female business leaders through a recruitment post approved by the ethics committee (see Appendix B). This page is commonly used to exchange industry information for upcoming jobs, training and development opportunities, and communications regarding unfavourable situations or patrons in Wellington hospitality businesses. Participants were encouraged to privately message me if they would like to voluntarily participate in the study according to the criteria provided.

Traditionally, sampling results in crucial features to the research design, where the qualitative process between researcher and participant is conceptualised against a set of criteria that is later embodied (Noy, 2008). With the research centred in feminist theoretical and epistemological approaches, it was evident that engagement with participants should be centred in holistic methods due to their status as a marginalised group (Woodley \& Lockard, 2016). To recognise the diversity of the female experience inclusive of their struggles as industry leaders, it was necessary to adopt a research strategy that created a comfortable environment and was accepted by my participants (Chilisa \& Nteane, 2010). For this reason, I adopted a snowball sampling strategy in social networking for recruitment to minimise potential marginalisation through biased subject selection (Woodley \& Lockard, 2016). The central limitation of snowball 
sampling has been interpreted as representativity, where subjects are not randomly drawn and therefore may rely on the personal bias of the initial contact (Dawood, 2008). However, given my position in the industry I wanted to extend the reach of my study to managers that were not immediately available for me to contact through online means, and may work in smaller, lesser known venues. During the recruitment process, I found the most experienced female managers were very excited about the project and put me in contact with other women who were at a high level in the industry. These connections were extremely helpful towards the study, and I gained access to a multitude of experienced women that was more reflective of diverse venues. In consideration of this, snowball sampling allowed for the dynamic of naturally occuring social networks to come to light, and allowed for a better range of participants (Noy, 2008).

Following the initial recruitment, information sheets (see Appendix C) were sent to all potential participants. I initally invited 14 participants, and 13 confirmed they would like to proceed with the study. Four participants expressed concern with the sharing of sensitive information that was particular to certain distressing events. Therefore, I developed a mechanism where participants who were concerned were sent the quotations included in the study via email so that they were able to give further feedback on identifiability and any necessary adjustments of which they were happy with. The final group of participants reflected a broad range of management role experiences across restaurants, cafés, and bars. All participants had a high level of experience, with the minimum experience across the group being 2 years managing, and 5 years employment within the industry. Participant profiles are presented in the table below:

\begin{tabular}{|c|c|c|c|c|}
\hline & Age Range & $\begin{array}{l}\text { Industry } \\
\text { Experience }\end{array}$ & $\begin{array}{l}\text { Management } \\
\text { Experience }\end{array}$ & $\begin{array}{l}\text { Current place } \\
\text { of Work }\end{array}$ \\
\hline Participant 1 & $20-25$ & 6 years & 3.5 years & Bar \\
\hline Participant 2 & $25-30$ & 6 years & 5 years & Restaurant/bar \\
\hline Participant 3 & $25-30$ & 7 years & 3 years & Bar \\
\hline Participant 4 & $20-25$ & 5 years & 3 years & Restaurant \\
\hline Participant 5 & $20-25$ & 6 years & 3.5 years & Restaurant/bar \\
\hline Participant 6 & $30-35$ & 13 years & 4 years & Restaurant \\
\hline Participant 7 & $25-30$ & 10 years & 9 years & Café/Restaurant \\
\hline Participant 8 & $20-25$ & 10 years & 2 years & Restaurant/bar \\
\hline Participant 9 & $25-30$ & 9 years & 7 years & Café/Restaurant \\
\hline Participant 10 & $30-35$ & 19 years & 13 years & Restaurant/bar \\
\hline Participant 11 & $20-25$ & 7 years & 6 years & Restaurant \\
\hline Participant 12 & $25-30$ & 9.5 years & 3.5 years & Restaurant/bar \\
\hline Participant 13 & $20-25$ & 6 years & 3 years & Café/Restaurant \\
\hline
\end{tabular}

Out of the final 13 participants, participant 10 had the highest level of experience, with 19 years in the hospitality industry and 13 years in management. The final group of 13 were drawn from 12 different companies (with the exception of two participants, who were not currently working together but were employed under the same company name across different sites/positions). There were 5 businesses that were individually owned with less than 3 investors, and less than two sites. The other 7 businesses had multiple sites across Wellington/New Zealand, with 3 investors or more, and more than two sites owned.

\section{Research Challenges}


Some initial challenges had an impact on the research process. Firstly, the research started on the $5^{\text {th }}$ of March, 2019. Unfortunately, due to some personal medical issues the thesis was suspended during my recovery from surgery from 01/08/2019- 31/01/2020. Due to my inability to undertake any study during this time, the process and application for ethics approval was delayed until the $21^{\text {st }}$ of February, meaning I could not begin recruitment or interviews promptly.

Upon gaining ethics approval, I performed my first face to face interview on the $2^{\text {nd }}$ of March 2020. Shortly after however, the worldwide pandemic COVID-19 (coronavirus) had started to gain traction in New Zealand with its initial introduction on $22^{\text {nd }}$ January 2020 and increasing number of cases thereafter (Ministry of Health, 2020). This caused widespread panic throughout $\mathrm{NZ}$ due to the serious nature of the virus causing thousands of deaths internationally. Both my participants and I were working during this time in forced close contact with a multitude of both tourists and local patrons, of which increased the level of general anxiety regarding how our work was being performed following Hospitality New Zealand's guidelines. My interview schedule was due to be completed by the $20^{\text {th }}$ of March, however due to the perceived risk of meeting with me face to face, I was only able to complete 5 of the interviews in person, and my progress was delayed. All other participants resheduled and opted to speak to me online using video calling, and my last interview was completed on the $2^{\text {nd }}$ of April.

Hospitality is an industry that has a low level of job security, and with a government announcement to go into mandatory quarantine (Alert level 4) by the $25^{\text {th }}$ of March, all businesses would be closed unless classed as an essential service (medical, supermarket) (Ministry of Health, 2020). During this time, NZ businesses affected by COVID-19 were able to apply for a wage subsidy previously discussed in chapter 2 . However, the subsidy was only granted for employee wage costs and the government negated to create a financial package for the hospitality sector to aid with business overheads such as rent/lease agreements. This meant that some business closures were inevitable. My participants expressed concern prior to and after interviews regarding their job security and potential loss of employment. Multiple participants were still awaiting approval for wage subsidy and had experienced huge financial strain.

Furthermore, due to mandatory quarantine I was not able to utlise the university/community printers/scanners or library. I do not own a printer for academic use, and therefore had to buy one the day before mandatory quarantine due to work commitments. Almost all stores were sold out of common goods due to community panic buying. I brought the last printer in stock, but it unfortunately did not have a scanning function which meant that submitting university documentation such as my 8-month thesis progress report was extremely difficult due to the requirement of hand written signatures.

\section{Interviews}

The five face to face interviews were conducted according to a suitable time and place for the participants, in local Wellington cafes outside of their individual workplaces. Cafés were selected that had outdoor areas so as we would be further distanced from hospitality staff when proceeding with the interview. Online interviews took place over video calling in my private home work space. I followed a set of semi-structured set of interview questions (see Appendix 
D), but remained flexible and allowed the participant to predominately guide the conversation. This was to further level the power dynamic in the interview process by ensuring questions were not following my own personal agenda but rather the interests and story telling of the participant (Hesse-Biber, 2010).

Due to my similar status as a female hospitality manager, the power dynamic was minimised through mutual empathy and the removal of a gendered hierarchy. It is known that the researcher can be viewed in a hierachical manner regardless of gender however, therefore the comfortability and level of casualness in conversation was important to promote its continual flow (Braun \& Clarke, 2013). Disclosures of experiences were advocated through participant story telling, and I responded with prompts of non-direct open questions, encouragement of reflection, and time to answer in a safe and respectful manner (Jack, 2010). It has been suggested that self-reflection through the process of disclosure is in itself, a validation of the experience (Hesse-Biber, 2010).

Before each interview I explained my position in the industry and motivation behind the study, to ensure that participants knew that they could discuss technical jargon or use slang language specific to hospitality businesses without having to explain their terminology. In face to face interviews a physical copy of the consent form (see Appendix A) was then reviewed and I provided an opportunity for further questions or concerns before proceeding. For online interviews, the consent forms were sent electronically. A small percentage of participants did not have access to a scanner or printer, and were happy to give informed verbal consent, of which was recorded against the date and time of the interview. I verbally reaffirmed participant consent to audio recording, and repeated the guarantee of anonymity with the changing of personal names, venues and business owners.

Because there was a component of the research taking the form of online synchronous interviews, I was mindful of both behavioural and social cues to inform the interview data (Salmons, 2016). By paying close attention to body language and the pitch/tone of the participant's voice I could gain further understanding in terms of how certain information effected interviewees both in person and online (Salmons, 2016). This was particularly important online as the barrier of a screen removed a small extent of casuality. My role as a female researcher was particularly advantegous however, as I utlised a feminist reflexive interviewing technique that involved disclosing snippets of my own personal experiences in relation to participant stories (DeVault \& Gross, 2014). This was in the aims to develop the women's experiences into moments of collaborative knowledge, to build and identify meanings between both researcher and participant.

All consent forms were signed before the interviews proceeded, and participants were made aware of their right to adjust any information in the resulting transcripts. The interviews on average took between 25-35 minutes. At the conclusion of the interviews all participants sent me their email addresses, and were provided with my university email address so I was able to contact them with data that would be included in the study. This was to provide a higher level of collaboration by revisiting and revising narratives produced together in the interviews (DeVault \& Gross, 2014). It also solidified a feedback mechanism for adjustments according to the participants privacy concerns. Participants were notified of any findings during the progression of the study. The data collection took place between early March 2020 and late April 2020 with the final number of 13 participants. 


\section{Data Analysis}

The process of analysis began with the transcription of the interviews verbatim, allowing me to look reflexively at how the participants were involved in the shared dialogue, with reflection on my personal interpretation, responses, and influence of feminist concerns (Acker, Barry, \& Esseveld, 1983). The initial transcription allowed me to become familiar with the nuances in language used, potential contradictions in participant accounts and emergent themes (Braun \& Clarke, 2013). In feminist research, DeVault and Gross (2014) highlight the importance of practicing careful listening to ensure there is an accurate depiction of the interview data in the transcription process, including non-lexical aspects of conversation such as intonation, hesitation and tentativeness. This meant I could interact with the interviews on a deeper level by engaging myself with the structure and organisation of language, aiming to empower each participant in repositioning them away from dominant discourse (Hesse-Biber, 2010). This was also particularly important in the 8 online interviews that were completed, as changes in body language and facial emotions were not as clear.

After all 13 interviews were transcribed, it was apparent that there were clear, reoccurring themes that emerged within the data (Braun \& Clarke, 2012). With myself being new to undertaking qualitative research, thematic analysis was used as an accessible method that allowed me to develop the core skills necessary for conducting qualitative analysis (Braun \& Clarke, 2006). It has been defined as a method that does not require a significant amount of theoretical knowledge, therefore easily learnt and applied by beginner researchers. It meant that I could identify themes relevant to specific my research question based on participant accounts and knowledge of previous empirical literature (Braun \& Clarke, 2013). It also meant that I was able to explore emerging patterns that were not previously considered to develop greater, multi-layered perspectives (Nowell, et al., 2017). Therefore, to promote trustworthiness and credibility in using this method, I used a systematic approach to my analysis that was transparent and could be easily repeated (Nowell, et al., 2017).

To start the process of identifying, analysing and coding themes I was aided by qualitative research software NVivo (version 12) by QSR International on a student license. NVivo is an application and tool for qualitative researchers that assists with managing data, by utilising a coding system that the researcher designs categorically and electronically (Smyth, 2012). NVivo also allows for the mapping of relationships between blocks of data and the creation of memos/reflections alongside coding and analysis (Smyth, 2012). This meant that I could maintain the trustworthiness of my analysis with a clear demonstration of the process I undertook in the categorisation of themes/codes (See Appendix E). NVivo has a very clear interface, meaning that I was able to upload all 13 transcriptions and systematically organise the large amount of qualitative data (roughly 8 pages of verbatim per transcription document) into initial themes.

I began by uploading my raw data of 13 transcription files and renamed them as documents/cases with unique identifiers that took the form of randomised participant numbers. These files were stored within the NVivo software program with archived dates, so I was able to accurately retrace my progression during the analysis and retrieve information at any stage. In the first stage of the analysis, I refamiliarized myself with the data by reviewing the transcriptions and generating ideas regarding potential themes or interesting insights (Braun \& Clarke, 2006). This led to the initial production of codes by simplifying the large body of raw 
data. This was performed by systematically identifying portions of the text in each transcription that related to an issue or theme, and indexing them into initial codes (King, 2004). I worked through the entire data set in detail and made note of any unique or similar aspects in a reflective diary that I kept during the analysis. After the codes were organised in the first phase, I ended up with 33 broad themes such as communication, advancement and misogyny. The data obtained was far richer than I had initially anticipated, so therefore I created a set of criteria to extract the most important, reoccurring themes in order to portray participants through their own words with the most dominant insights (Charmaz, 2014).

To do this, I identified the codes with the highest amount of references (paragraphs or sentences allocated to the code) in the NVivo software. I then compared this with the codes that had the highest cross-data correlation. I followed this process in my reflexive diary and came up with a criterion to analyse the significance of each code. The criterion measured themes by significance and revealed dominant codes as those that had over 30 references or more, with over 10 cross-data participant mentions. There were 17 codes mentioned by over 10 participants. There were 16 codes that had over 30 references. I collated this information and condensed my first phase coding according to the above criteria into 14 themes. In the second phase, to ensure that I was extremely thorough, I explored these in depth by creating 3-4 sub codes per theme for a more detailed depiction of the direction that the data was taking. In the final phase, I transferred all 14 themes and subcodes into headings on a word document, so I was able to visualise patterns across a detailed data collection in a clearly written format. This was significant for the analysis, as there was huge repetition of patterns across sub codes.

Because I am very influenced by visual stimuli, I printed the data and highlighted visible thematic patterns whilst keeping large sections of the data intact (Grbich, 2011). In the final phase, four dominant themes were made clear across sub codes, which were generalised as headings: misogyny/gender stereotyping, advancement, old boy's networks, and professional development. Under each heading there were three to four sub codes relating to the dominant theme. These themes and sub codes were outlined in the final design of the findings located in chapter 4.

\section{Reflexivity}

Traditionally, feminist research underlines the importance of using a holistic reflexive approach as a methodological tool for analysing researcher positionality, deconstructing power relations, and the review of the creation of knowledge (Hesse-Biber \& Piatelli, 2014). Reflexivity was continuous throughout the entire research process and was not confined to a singular stage (Weisman, 2017). In redirecting positivist conceptualisations of objectivity, I aimed to be critically self-reflexive in the knowledge of the multiplicity of meanings developed through interactions, that could be influenced by my personal perspective of the social world (Hesse-Biber \& Piatelli, 2014).

Relfexive engagement led me to examine assumptions that I did not previously consider. For example, one of my participants had experienced discrimination when becoming pregnant at work. I was confronted by my own ignorance to the impact of oppression in such a signficant time of her life. In reflection, this experience shaped a counter-hegemonic conciousness as it was shared from the vantage point of the oppressed rather than the oppressor, providing a critical insight into a unique perspective on an important ethical issue (Collins, 2000). I had a 
responsibility however, not only to document/have awareness of my own ignorance or assumptions surrounding the operation of discrimination, but create new ways of thinking to disrupt it (Gallagher, 2000). I did this by purposefully directing questions in interviews to allow for participants, and therefore myself, to reflect critically on any structural advantages/disadvantages they may have experienced and the influence they might have had their careers (Gallagher, 2000). This ensured that there was deeper reflection, and I was able to challenge my own interpretations of dominant discourse by acknowledging and giving voice to the prescence of inequalities (Gallagher, 2000).

Participants provided self-presentations describing their work and leadership styles with agency throughout the interviews, and I reflexively drew on my own personal experiences as a woman to pick up on lexical downplays of sentences and stories during analysis (DeVault, 1990). These were stories followed by “maybe", "I'm not really sure", "It doesn't really matter though" in light of events that were significant. This approach utlitized by DeVault (1990) allowed me to view the use of language as an insight into participant experiences, yet simultaneously allowed myself as a researcher to authenticate these stories by engaging and stimulating further responses. I wanted to deconstruct the power relations between wider society and my participants, by changing the notion of "it doesn't matter" into exploring the self in context, with questions such as "but how did that impact you?", or "how did you negotiate the challenge in your position?". In this light, reflexivity was used to problematise social relations within the workplaces under discussion and ultimately uncover what wider invisible barriers or influences shaped the experience (DeVault \& Gross, 2014).

Reflexivity therefore allowed me to become more sensitive to power relations in participant accounts during the research process. This was challenged slightly with synchronous communications in my online interviews, as the conversations were less organic and limited my ability to take quick notes (DeVault \& Gross, 2014). This meant that I was able to peform reflections after the interviews but my real time reflection on behaviours and mannerisms displayed by participants was minimised compared to face to face research. This was not necessarily a detriment to the research however, but it changed the way in which I reviewed my reflexive practice, and provided me with the opportunity for deeper reflection after the interviews (DeVault, 1990). This was particularly noticable with one participant who took a long time to respond to questions online, due to both thoughtful responses and a busy/distracting household in the background. For online conversations participant environments were variable, with the added pressure of mandatory quarantine meaning that a quiet place in the privacy of a participants home was not always available. This did not limit participant interest in the study but sometimes detracted from immersion in conversation, meaning that I had to utilise increasingly reflective language to develop the topic under discussion on occasion (Davies, et al., 2004).

\section{Trustworthiness}

Although reflexivity is important in establishing trustworthiness in the data analysis process, this research also followed other criteria according to Lincoln and Guba's (1985) qualitative research guidelines for credibility. Previously outlined in the current chapter, member checks were utilised not only to limit identifiable details, but further validate the authenticity/accurateness of participant accounts. This allowed for opportunities for further critical details to be shared, corrected, or summarized in the participants own words. Credibility 
was also established through my personal prolonged engagement in the research setting from previous/current work experience, meaning that I was intently familiarized with hospitality cultures and understood any preconceptions I may have had entering the interviews.

Due to this engagement, I was able to garner thick descriptions in interviews by building a strong rapport with participants, to allow for in depth story telling (Hesse-Biber, 2010). This allowed me to evaluate patterns of socio-cultural relationships by placing them in context. Throughout this process, I was extremely careful to produce a transparent audit trail of all raw data (including handwritten field notes), transcriptions, and concise process for thematic coding using NVivo qualitative software. This meant that the process undertaken for the investigation could be easily repeated, and established confirmability (Lincoln \& Guba, 1985).

\section{Summary}

This chapter informed the research methods by outlining the feminist epistemological and methodological approaches utilized in the study. These approaches ensured that women's experiences could be shared with agency, and participants were prioritised in separation from dominant discourse. Reflexivity was used to examine my social position as researcher and view my involvement and influence in the interview process. Trustworthiness features were implemented to ensure the degree of confidence in data, interpretation, and methods. The following findings chapter will explore the dominant barriers to career development for female managers and the ways in which they are enacted in corporate practice with connection to wider socio-cultural contexts, by analysing key issues highlighted by participants in the data. How participants navigated their gendered leadership roles and related organisational pressures will also be discussed in relation to the scope of the research. 


\section{Chapter 4: Findings}

The research aimed to highlight the multiple, intersectional barriers that effect female hospitality professionals in the Wellington, New Zealand region. The following findings will outline how the production and maintenance of these barriers impede women's attainment of a management position and enactment of leadership. Further investment into the improvement of working conditions and organisational operations will also be explored in the context of the localised hospitality sector. The findings will be approached under a post-modern feminist lens, previously outlined in the methodology section to disrupt dominant discourse and privilege the complexities of different realities presented in participant accounts. Participant verbatim was used to reflect these experiences as they were expressed, further ensuring trustworthiness of the data (Braun \& Clarke, 2013).

The research context is localised to the capital region of Wellington of which has the highest growth in the NZ hospitality sector (RANZ \& Statistics, 2020), implying that the present findings are significant in their contribution to the industry nationwide, however limiting generalisability. This should not affect the credibility of the results, but instead provide insight into the social-structural dynamics of organisational cultures and appearance of the glass ceiling from localised participant perspectives. The findings will be reviewed under each section of the chapter, with a discussion following each critical idea relating to existing literature and other considerations. The findings will begin by discussing the interplay of gender stereotyping and misogyny on industry, customer, and organisational levels. This will include a discussion of LGBTQ+ environments. Next, barriers to women's advancement/promotion will be reviewed, followed by the exploration of old boys' networks and perceptions of their operation within the industry. Lastly, professional development will be discussed in the context of improvement for the working conditions of female managers.

\section{Finding 1: Gender-Stereotyping/ Misogyny}

The most significant cross-data theme that was experienced by all 13 participants was the varying levels of misogynistic behaviours and attitudes towards women by male employees, customers, or business owners. These behaviours were described in conjunction with genderstereotyping. The key areas in which misogyny was described on the industry, customer, and organisational levels, which will be discussed in the following sections.

\subsection{Industry level}

One of the main themes highlighted by participants was the gender-stereotyping of roles in the hospitality industry. This was a focal point for most participants, with influences from both the social environment and workplace practices impacting the dichotomous relationship between male/females in the organisation.

Participants expressed a difficulty with women's consignment to gendered positions as a barrier to advancement. For example, one respondent explained "I think that they emphasise the difference between men and women in the hospitality industry: women are supposed to be 
compassionate, empathetic. Women take up roles typically like waitressing. So, I think a lot of women are minimised to these roles". This was continued with "women are consigned to certain roles, and that's all we are ever really good for...women aren't generally given bartender roles, because bartending has always been thought as a man's job" (Participant 5). Gender segregation across the industry level described by participant 5 was characterised across participant accounts in both general and first-hand terms. For example, participant 12 expressed "I have found that I have been thrown quite often into waitressing: despite that I have never waitressed in my life before I moved to NZ, just because I am a female. I am actually a bartender" (Participant 12). This indicated that lower level roles in the industry were characterised by masculinity/femininity, and consequently could account for the high visibility of women in waitressing/front of house roles. There was an overarching perception that venues across Wellington "seem to have a divide of boys on the bar, girls on the floor" (Participant 12). The socially created dichotomy of boys/girls in separate roles was characterised by sexstereotyping, and therefore acted as a barrier to women's advancement.

Eagly, Wood and Johannesen-Schmidt's (2004) social expectation theory discussed at the beginning of the literature review may account for the sex-stereotyping of roles in hospitality organisations due to the feminisation of positions requiring higher levels of customer interaction and 'care'. This was indicative in participant experiences of generalised beliefs regarding their suitability to front of house roles, even with no prior experience performing in areas such as waitressing. This has been acknowledged in previous research by the visible abundance of women occupying low level personable positions (Baumgarnter \& Scheider, 2010) that are stagnant in their advancement within hospitality organisations (Clevenger \& Singh, 2013). The gendered performance of roles was highlighted as an industry 'norm', and consequently created sex-expectations for women to be "compassionate, empathetic" highlighted by participant 5 . This suggested that broader socio-cultural discourse operated through the industry level, as women had to both perform in feminised roles (Carbey, et al., 2003) whilst maintaining gender-related attributes such as approachability and consideration (Eagly \& Karau, 2002). Under speculation, these findings provided a strong indication for generic hiring practices dependent on the implicit gendering of waitress/bartender positions, which is consistent with the visibility of women in lower paid roles.

\subsection{Customer-level}

In contrast to industry norms, participants had also faced difficulty when they performed in positions traditionally occupied by men, which was especially evident in specialised sectors of the industry. This was due to broader social beliefs that negated to include women in the discourse of leadership of which was problematized by participants. Two respondents stated:

I had one guy when I was working back *overseas ${ }^{1}$ turn around to me and say, 'are you a whisky chick?' and I said, 'what on earth is that?'... just because I was managing the distillery. Or guys being like, can you get one of the boys to explain to me which whisky to go for? And it's like, well I actually know more than most of the boys here. (Participant 12)

I think from the customers as well, or just general society I feel like you are less valued in your role as a woman, because you are not the face they want to see behind a craft

\footnotetext{
${ }^{1}$ In all other quotations, asterisks have been used to indicate that fictitious details have replaced identifying information on behalf of the participant.
} 
beer bar, and they will immediately direct their questions at men, or ask to speak to manager: assuming you aren't the manager or couldn't be. (Participant 3)

It was found that participants had to negotiate their knowledge, experience and position in specialised areas such as whisky or craft beer bartending due to the masculinisation of these roles. Both participants expressed their concern with ingrained social beliefs but concreted their relative agency in their position even when confronted with unjustified assumptions. However, the minimisation they experienced contributed to a heightened need to 'prove' their credibility that was not automatically assumed through attaining a management position, shown further in the following example:

I have a sisserpon qualification which is basically like a sommelier qualification but for beer, but customers would constantly ask the man behind the bar for his opinion on a beer even though they may have just started a week ago, and I have actually got genuine, tangible stuff under my belt to show that I am good at it. (Participant 3)

Participant 3 illustrated that her qualifications and experience were rendered invisible by customers through the automatic assumption of a male in power. Therefore, men in lower positions were elevated above her even if "they may have just started a week ago". Stigmatisation in a management position was experienced by the majority of participants in different descriptions, displayed by predominately male customers. Participant 4 explained the relative stigma as 'things like 'oh get the manager', but you are talking to one, but they will say 'No, who's your boss?'...I am the boss of front of house, you know?'. Further, participant 8 reported her struggles with male customers who had issues in her restaurant, for example: "I find it also when a customer comes up to pay and they want to speak to a male manager specifically". The general disbelief against women in leadership was therefore a prevalent issue, of which was indicative of broader industry norms previously discussed in section 1.1, of which supported differences surrounding men and women's hospitality work.

It was found that glass ceiling barriers still existed for women who had attained a management position and were enacted through customer's verbalisation of broader socio-cultural beliefs surrounding men's suitability and dominance in leadership. This was portrayed through a discourse of misogyny, depicted further by participant 11 with male customers "not listening to you because you're a female", and participant 12's acknowledgement that it was "difficult" dealing with "mainly male customers, being a female". Another commented "people, usually men, have assumed male staff below me are in charge... even though I am visibly taking charge" (Participant 9). Assumptions of authority therefore increased both the psychological and physical workload for women in hospitality management, as historic notions of sex-based roles were reified by clientele to participants' discredit.

The research was consistent with Oakley's (2000) analysis of the 'double-bind' theory, wherein employed women must simultaneously conform to gendered expectations whilst balancing professionalism and aptitude in their positions. It was clear that social ideologies encompassing the traditional notion of a men in top hierarchical positions prevailed in hospitality settings (Perez, et al., 2019), and ensured the failure of women's credibility in leadership (Oakley, 2000; Regine \& Lewin, 2003). The interactions described in participant's experiences exemplified the 'natural' occurrence of masculinity and its ritualistic normality in positions of power (Connell, 2001). A male consciousness solidified by customers therefore provided a clear obstacle to women's performance in a management position. Rather than operating as a 'subtle' form of discrimination for women who had broken the glass ceiling in other industry settings 
(Meyerson \& Fletcher, 2000), these findings were a deviation from existing literature. This was due to the operation of stigmatisation as a function of misogynistic social discourse that was interestingly unhidden, pronounced and accepted in hospitality organisations as a customary component to women's daily management obligations.

\subsection{Organisational level}

Gender stereotyping occurred within organisations in conjunction with misogynistic attitudes demonstrated by senior management and staff. A culture of detrimental segregation was described by participants through the development of 'lads' cultures that stimulated the solidarity of male bartenders and exclusion of women in all positions of the hierarchy.

Participant 12 highlighted that in her workplace "it was the boys that called themselves "top shaggers' and it was lads lads lads, the boys on the bar, the girls on the floor". This physical/cultural segregation was further supported by participant 13, as she expressed that "it is very unlikely that you would see one of our bartenders leave the bar and drop the drink at the table. They will wait for a female waitress to come and grab it". Participants highlighted that the physicality of the restaurant floor was stigmatised by its feminine association, whilst the bar was reified as an elite place of power in the male domain. This was manifested through the dubbing of misogynistic cultures as "the bar boys' group", illustrated by participant 13 as "a little clique" based on negative attitudes towards women.

Participants described the operation of these collectives as exclusionary in nature, however significantly reinforced when senior management teams participated. For example: "There was very much a sort of, boys club mentality. Which, because *the boys would drink with my boss, and they would all hang out, so there was the social aspect to when it came down to dealing with the 'lads' issue. It took a long time for me to get heard" (Participant 12). In a similar vein, another commented that "especially in the company I used to work for, male managers would get clothing allowances and all these other perks, where the owner would buy them stuff/gifts, and female managers were treated almost like children" (Participant 4). Participants highlighted the amplification of misogynistic attitudes when senior management actively participated in the solidarity of 'bar boys' groups, which transcended collective action to include physical perks in the experience of participant 4. Participant 12 clarified further that when confronted with the "boys club mentality" she "literally had no authority or respect!". These collectives operated in the unquestioned favourability of men in the organisation, and significantly impacted women's ability to perform in management due to their perceived lack of authority based on gender.

In alignment with Mooney and Ryan's (2009) empirical research in an Australian and NZ hotel group, it was found that men automatically assumed credibility and power through informal networking whilst women had to work harder to professionally establish themselves. This reflected that male solidarity was maintained or established not only through hierarchical, professional positions but through privileged 'boys' groups that relied on the informal power advantages of male friendship (Mooney \& Ryan, 2009). It was evident in participant accounts that the production of these cultures was solidified by both behaviours and physical segregation in restaurant settings, wherein the dominance of men in bar positions contributed to the constitution of oppression in the organisational hierarchy. The absence of diversity over different areas in the business dynamic contributed to men's superiority over women on intersectional levels (Connell \& Messerschmidt, 2005), with the implication being that 
customer beliefs, industry norms, and segregation in workplace roles were the dominant contributors to the maintenance of the glass ceiling against women's professional performance.

\subsection{Organisation level: LGBTQ+}

The three interactional levels of oppression centred on customers, industry and the organisation have been discussed from participant experiences of cis-normative ${ }^{2}$ relations and heteronormative ${ }^{3}$ venues. However, the findings suggested that LGBTQ+ venues may not reproduce glass ceiling barriers to a similar extent, reflected in the following:

Working in a queer venue/community, many things have enhanced my experience as a female manager, both because there were less gender-normative expectations, but also because being a member of a close community for such a time assures a level of acceptance and support...my manager at the time that I got my DM cert and was promoted to general manager, was male and was very active and encouraging in mentoring me in management...I have been lucky to work in environments where there are perhaps less gender obstacles than in others; but if even in those circumstances I have experienced the obstacles I have - that is an indication of how much worse they must be in more cis-normative workplaces. (Participant 9)

Participant 9 was an outlier in the findings due to her experience in an LGBTQ+ venue, exemplified in the above extract. She described the renegotiation of patriarchal oppressions through her professional incorporation and (male) senior managements support for her to advance in leadership. This provided a sharp contrast to other participants descriptions of heteronormative venues, wherein they were subject to strict social punishments under intersectional oppressions on behalf of male collectives. Participant 9's experience could not be generalised as descriptive of all LGBTQ+ venues nationally, however provided an insight into women's oppression. Her reflections accentuated that detrimental cultures could only be reproduced by men across multiple levels when they were active participants of misogyny. Although she still experienced a small amount of customer-related resistance to her leadership, she acknowledged that it must be "worse" in "more cis-normative workplaces".

Wahl 2014 found in a study of male managers that men themselves were the predominant 'change agents' in challenging cultural normalisations or organisational practices (Wahl, 2014). This was pertinent for the current findings, as the absence of gendered expectations for participant 9 meant that she was able to flourish professionally due to a change in discourse. In a similar vein, Brickell (2009) noted that the power associated with sexuality could be redefined and negotiated against different social regulations, which was reflected in the operations of the LGBTQ+ venue exemplified in this section. In previous studies it has been found that changing the levels of awareness around complicit masculinity can reduce gendered issues in the workplace, of which was evident in participant 9's experience of male senior management (Connell, 2000; Wahl, 2012). Men in her workplace had a heightened awareness of, in her words, "misogyny" and subsequently interrupted inequalities that commonly occurred across intersectional levels in heteronormative environments. This clarified that in this research, patriarchal oppressions across industry and organisational levels could not be viewed as stagnant, but relied on the influence of their stakeholders to function as a social reality. This

\footnotetext{
${ }^{2}$ Cis-normative is the term derived from cisgender that pertains to an individual who identifies with the sex they were assigned at birth. Cis-normative denotes the societal assumption that all individuals are cisgender.

${ }^{3}$ Heteronormative is used as a term to describe the normalisation of heterosexuality that is promoted or preferred in most social settings.
} 
was a significant finding for future research into the betterment of the hospitality industry, by underlining the importance of men as the majority influencers in the situmulation of cultural reform.

\section{Finding 2: Advancement}

A main finding in the research was participant's experiences of a notable lack of advancement due to external oppressions. The cultural background for promotion to a managerial position in NZ highlighted that on average, kiwi born participants with exclusive experience in a localised context were able to gain a DM position after an average of 1.88 years. Participants who had international experience (U.K/Australia) before working in $\mathrm{NZ}$ on average took 6.37 years. This provided a strong indication of minimal training/support within the local industry, as 12 participants had received no formal professional development or management training after gaining their DM's certification in NZ, but were able to gain the qualification quickly.

\subsection{Operational Performance}

The findings illustrated that those employed in positions of senior management/ownership were the greatest barrier to the betterment of performance for participants daily managerial operations. There were 11 participants who described a plethora of discriminatory instances that effected their position in the hierarchy and professional development. The follow examples explore these circumstances:

But then once I moved to *another business as the general manager I still- I was 19 at the time- or just turning 20. I had already done the LCQ side of it so all I needed was to get the manager's certificate... it kind of became an issue [to the owner] that was not important. He put everyone else through who was actually old enough at the time to sit their duty managers... and he was like 'oh, I don't really need you to have one'. I said to him well you kind of do because I am your general manager, and he didn't have a bar of it. I never actually got my duty manager certificate until- even though I was fully managing everything- I never got my certificate until June of last year. (Participant 13)

I voiced my interest that I would like to do my managers and LCQ, they offered to pay for it and they did, and then they basically came back to me and said, we have paid for this but we actually don't have any management roles available for you. So, I said that's a waste of time. (Participant 5)

A common theme in the findings was participants quick ascendance to a DM position without adequate support from senior management. This was highlighted through different variables in both participant 13's promotion to general manager without a legal certification, and participant 5 's confinement to a lower role even after obtaining qualifications. It was found that the guise of advancement was frequently a tokenism to maintain appearances, rather than actualised in the organisation. This meant that participants general performance was diminished in a lack of clarity surrounding their position, highlighted in the below examples:

There would be male managers that would work quite closely together, and they were in upper management, and so they would have discussions together, or maybe they listened to your idea and said yeah we will talk about it later, and nothing would ever get done. (Participant 6) 
You get into a management position then feel like there is nothing else. For example, in the stage that I am at now, I haven't been taught to do anything else except manage the floor. Whereas the males have all been taught things like ordering stock, things like rostering and all the admin side of things. I haven't even been asked or shown if I want to do any of these things. (Participant 8)

It was found that an organisational glass ceiling was maintained in the exclusion of female participants from formal decision making and daily operations. Both participant 6 and 8 described how they were visibly minimised in day to day functions when performing in the same position as their male counterparts. General workplace operations were disadvantaged due to the rejection of female leadership, despite participants desire for learning and success exemplified by participant 8 . These sentiments echoed a prevalent cross-data theme wherein achievement was individualised in lieu of collaboration or support in the workplace.

Meyerson and Fletcher (2000) highlighted that gendered cultural norms in the workplace inevitably support subtle forms of discrimination despite the appearance of female leadership, discussed also in section 1 of the findings. This research was consistent with the above participant examples, wherein a lack of immediate support for participants ascendance into managerial positions created an unequal distribution of authority in hospitality organisations, and therefore supported underlying discrimination. Participants expressed their own assertiveness/confidence in their navigation of structural issues within the organisation, however, these circumstances were undoubtably made a personal responsibility to overcome. In alignment with the current findings, Acker (1990) found the individualisation of women to become responsible for their professional advancement ensured their isolation within the organisation. Thus, the appearance of the glass ceiling was maintained through a neoliberal rhetoric of individual responsibility for training, learning and performance during on-site daily operations.

\subsection{Promotional Access: A View from the Top of the Hierarchy}

It was found that the promotion of women to DM positions was unsupported in the previous section. However, once attaining a managerial role, participants described being subject to higher levels of discrimination through the experience of power/dominance relationships. This was explored clearly by participants who had achieved top-tier roles in the organisation such as GM, 2IC or restaurant manager:

I think the main thing is that you get a lot of older males specifically in management or in other roles that don't necessarily take you seriously as a female. They kind of shut you down, saying 'I have been in the industry longer' or 'you're a female, let the big boys handle this'. But it's very rare to experience that- at least in my role [GM], but I have been at the same place for the last four years, so I haven't had too much experience with other people. (Participant 1)

Participant 1 elucidated that she was not taken "seriously as a female" wherein her ability to progress was minimised due to prevailing industry attitudes centred in misogyny. There was reluctance in explaining her experience, wherein the juxtaposition of "it's very rare to experience that" highlighted a clear contradiction to her initial explanation of repression. This indicated the avoidance a victim mentality, in favour of generating professional agency in protecting the appearance of her top position within the hierarchy. This was a continued theme for other respondents: 
I think he is a little bit prejudiced towards females: in my experience of 3 years... you have to be very clear cut but submissive. If you show any sign of dominance or form of leadership with your opinions, then it does not go well. You must be submissive.... he has put things in place such as different roles or managerial tasks of which I have succeeded in pretty much all of them. I don't think he will ever, unless he is put in a hard place, push me forward.

(Participant 7)

Patterns of domination and submission created an underlying discourse of oppression for female leaders in the industry. Participant 7 reflected on this theme in which she felt it was necessary to modify her position to "be submissive" in order to succeed in "managerial tasks" yet unable to cultivate professional progression. This echoed participant 1's account wherein misogynistic cultures created an obstacle for her performance, even after the attainment of a GM position. Another GM reflected further:

It was getting past the point of DM that I found the most difficult... there was one guy that I worked with who started at the same time as me, and he didn't even have his DMs but was made an assistant manager before I was. I was really unhappy about that. So, I made them aware that that was not what they should be doing: he wasn't even that qualified, it was his first hospitality job, and it didn't make much sense. (Participant 3)

Although participant 3 had gained a GM role by the time of the interview, she described her journey to promotion with frustration due to the favouring of unqualified junior men. Both participant 3 and 7 illustrated discriminatory promotional practices in which women's work was generally perceived as less valuable than their male counterparts, regardless of formal certifications and experience. Promotional opportunities were catered to male employees in the form of gendered accessibility, described in another account:

I went for a job- one of the GM positions came up at our place, so I went for it, and one of the things that came back to me was the fact that I wasn't 'nurturing' enough, I actually think that's a really ridiculous thing to say. I don't think that would have ever been said to a single male in our profession... but if you look at the new GM, he's not nurturing, because he doesn't need nurturing...I think the only reason that they expect that from me is because I am female. I very much doubt that any of my male colleagues have been asked to be nurturing. (Participant 10)

The socio-cultural expectation of women to balance femininity with assertiveness/leadership in organisations manifested participants perpetual deficit in their adaption to gender-based attributes. This was echoed by participant 6 in her position as a restaurant manager, as she explained that "you have to prove your worth" as a woman in a higher capacity. In addition, participant 3 explained that "it also makes it harder for you to show your strengths in your role... because you are not given the opportunity to". Higher competency testing including gendered expectations was a focal point for participants in discussing their progression. The procurement of femininity and submissiveness to the male ideal was an undermining factor for both gaining promotion and retaining high level positions in hospitality organisations.

Oakley's (2000) 'double-bind' theory was reiterated in the current discussion wherein participants professional credibility was minimised against gendered expectations, clearly 
illustrated by participant 10 . Women described their inferior status in oppositional discourse to men, even after 'breaking' the glass ceiling in top positions of the hierarchy and obtaining the appearance of success (Elacqua, et al., 2009). The professional progression and retainment of agency was negotiated by participants differently, reflected in participant 1's lexical downplay of personal difficulties. Her initial response was irregular and contradictory, however upon further analysis her clear avoidance of a victim mentality was utilised to negate the effects of discrimination. This was a common strategy found in empirical research of female managers, thus signifying the current findings in this section were consistent with existing literature (Kantola, 2008; Ng \& Pine, 2003). In contrast, participant 7 aimed to modify her gendered position for success (Broadbridge \& Hearn, 2008), by conforming to a required "submissiveness" whilst endeavouring to perform in managerial tasks. Gautier (2002) found that women in top positions of the NZ workforce challenged maternal stereotypes, reified by participant 10's account in which she refused to accept "nurturing" as a standard for promotion (Gautier, 2002). Thus, female hospitality managers who were in high positions of employment were made to continuously reposition themselves against a dominant male ideology when applying for promotion or retaining the appearance of authority in their roles.

\subsection{Sex-based discrimination/harassment}

Sexual harassment was a common occurrence experienced by all 13 participants on multiple levels. In the most extreme cases, sensitive circumstances were silenced through unjustified responses on behalf of male senior management teams. In the following example, participant 2 was subject to financial strain through a loss in hours/salary after disclosing she was pregnant, and thereafter was subject to bullying/harassment from management:

When I was 5 months pregnant, I was still managing shifts... then eventually my shifts got shut down... which meant that my pay went from a salary full time contract, to a percentage wage. I didn't feel like I was supported, I definitely felt like my hours were getting cut shorter, not because they were helping me, but... because I guess they had an issue with me. We eventually did come to an understanding, being able to come to an agreement- but even that was still quite far into my pregnancy where I had maybe a month or two months before I was actually ready to finish anyway. So, I worked my maternity leave right up until two weeks until my due date....I would probably put it on the verge of bullying. (Participant 2)

The key finding shown in the above example was how power in management was wielded over vulnerability, in a situation coloured by financial and emotional strain. This manipulation rendered her situation invisible against the oppression and "bullying" occurring within the business. In her experience, she described no formal communications surrounding her hours, or discussion of healthy and sustainable reductions in work for both the business and employee. This 'agreement' took 7 months to be erected, with a requirement to work up until two weeks before her due date. The impact of severe discrimination therefore hindered her professional progress and created unethical informal consequences, of which was also experienced by another respondent:

I have had experience with the owner and his friend group, and some very bad things happened [sexual assault]. This affected my ability for promotion because I would be having to work a lot closer to *the owner, and now his friend [perpetrator] isn't allowed to come in anymore. Because of the incident that happened. Yes, I should have felt safe to enjoy a drink after work. But he bought in a negative environment and people who 
should have not been there. Obviously, nobody knew that this sort of stuff would happen but obviously, bringing that sort of atmosphere into a business should be monitored regardless: everyone is just getting drunk which in itself is illegal...

why have I not been promoted? This is because *the owner and I do not see eye to eye. Which means when I voice my concerns, he does not like it. (Participant 7)

The protection of male privilege in power positions was introduced and solidified in dealing with traumatic events on behalf of participants. Management practices were absent of ethical boundaries due to the secondary nature of employees' wellbeing. Exhibited in participant 7's example, the personal punishment for traumatic circumstances was translated onto her employment status through the abhorrent actions of a third party. She explained that her sexual assault "affected [her] ability for promotion" even after 'resolving' the situation by trespassing the perpetrator, who thereafter visited the premises on several occasions. The psychological and physical effects of severe trauma were ignored for the short-term interests of male owners, experienced in another participant account:

I have gone through a lot of issues with bosses when it comes to the way that they speak to you as a female- one of my old employers asked me to sell my body because his company was going down. He basically asked me to be a sex slave for him... that kind of stuff is very traumatic because you feel worthless... you get that a lot in hospitality...

A few weeks later this lady kept coming in, always wanting to chat with me, always wanting me to serve her table, it got really weird for me... then one day the owner turned around to me and said, sit down I have something very serious to ask you. The lady said that she would like you to work for her, doing happy endings. She would then help me get out of debt... I told him I don't need to go home and think about it, I can give you my answer right now. No! and you can take this as my notice... I didn't give a shit- I came back the next day and handed in my notice. (Participant 13)

Participant 13 illustrated her inability to negotiate with sensitive/illegal circumstances because of the influence pertaining to power/dominance in the hierarchy. An underlying heterosexual social discourse confirmed the subservience of women to men, demonstrated through participant's experiences of a complete lack of ethical boundaries/social consciousness in the industry. In participant 13's example, the male owner involved assumed her subordination both professionally and personally. The highly traumatic experience was reflective of repeated exertions of control with inappropriate expectations. It was therefore found that NZ law and contractual agreements in direct relation to ethical hospitality practices did not serve to be a limitation for a portion of male owners in the industry.

Sexual harassment was also found to be the most repetitive on behalf of male customers towards women in the industry at all levels. For example, participant 6 stated "we have had a customer harassing staff with sexual comments and touching them inappropriately... for a number of months" of which she dealt with accordingly by refusing service. Participant 11 reflected that sexual harassment was "Super common! Every single day". These examples were primarily in concern with the accessibility of females to customers in areas such as waitressing, whereby situationally they had closer on-site consistent contact with male clientele. Participant 7 reflected on this further with "the girls are targeted in this industry due to alcohol... you see it all the time. It is very disgusting". It was evident that harassment occurred on multidimensional levels, from customer to employee, and from senior management/business associates to female managers. This demonstrated that women's sexuality frequently 
disempowered them with their navigation of consistent bodily violations, thus reflecting the systematic unconscious of the male gaze.

Hearn and Parkin (2003) found that sex-based discrimination and harassment is not limited to direct physical violence but can be generalised as 'management practices'. Participants in the current research described management practices as the enactment of domination, subordination, and violations (Hearn \& Parkin, 2007). The authority of men in management increased their opportunities to exercise power in more repressive forms (Hearn \& Parkin, 2003), of which coincided with the heightened ability to silence complaints, especially for extremely shocking/illegal circumstances that were highlighted in the examples throughout this section. This accentuated the normalisation of detrimental management practices that remained as a naturalised ideology by ensuring the continued domination of men over women both psychologically and physically in the industry (Collinson \& Hearn, 1996). For both participant 7 and 13, it was clear that the situational and contextual constraints of heterosexuality in the hospitality organisation manifested extreme levels of violation (Gavey, 2012; Mulvey, 1975). Waudby and Poulston (2017) found that power imbalances centred on differences between age and experience made it difficult for women in NZ bar/restaurants to repel customer sexual harassment. This finding was not entirely consistent with the current research, as alternatively power imbalances were clearer in the organisational hierarchy under the actions/behaviours of male owners. Female managers found themselves both disenfranchised due to the influence of sexual harassment from the highest levels of the organisation (Carvalho et al., 2018) and further were abject to a regulation of persistent gender inequalities that stemmed from these experiences.

\section{Finding 3: Old Boy's Network}

The old boy's network functioned in the central Wellington hospitality industry as a system for preserving privileges and power advantages for men at the top of business structures to the exclusion of women. Eleven participants had experienced or observed the functioning of informal male networks that had directly affected their performance or had detrimental business operations in favour of the recreation or friendship of these groups. Participants described these networks as either:

1) A collective of male employees ('bar boys' groups' covered under section 1.1),

2) A collective of male managers, or

3) A collective of male owners and their male friend groups.

\subsection{General Informal Male Networks}

It was found that competition, opportunities for advancement, and power advantages that are traditionally found in the formal organisational structure were redistributed informally by male networks. Participants described the reinforcement of these groups to ensure that male power and status were maintained at the top of the hierarchy. This was especially prevalent for male owners who could enjoy these cultures without challenge to their normalisation, highlighted in the participant accounts below:

Yeah, one of the owners is notorious. He just does not care what he makes his staff feel, he will override their authority on everything, he will override decisions on the licence of the place to show off to his friends... he will completely override anything that you should be enforcing as a manager. (Participant 3) 
there is also a *VIP card- now anyone who carries this *VIP card are the worst customers you will ever see... because they think they are a part of this 'clique'. I have never seen a female with a *VIP card.... it gives them like a *huge discount which is ridiculous... they have shares in the business or something like that. I really don't know how people get a *VIP card. But the people who do are all very old sleazy males. (Participant 13)

A focal point for participants was the maintenance of an 'old boys' network that disregarded female managerial delegation. Participant 5 described these networks as "an 'old boys club' in hospitality...people in power who obviously have access to special platforms". In a similar vein, participant 12 explained "the owners are renowned for treating the newer venues like their playground". The implication between professional obligations and illegal recreational activities that coincided with the drinking/intoxication of informal male groups had to be negotiated with by female managers. Participant 13 described the influence of "VIP" collectives who were privileged with discounts and illegal consumption of alcohol wherein she had been told she "cannot cut that person off, even if they were lying on the floor". The advantages of these groups therefore privileged both physical rewards and inappropriate behaviours. This was explored further:

For example when you look around at the people who are managing restaurants, it's just ingrained in them because that's kind of- they have always been given this [male] privilege... there is quite a lot of 'pack mentality', I would almost say... it's very much like a 'we are the boys' attitude... I definitely feel like you do hear comments... how females look, you know, there has been comments made about how females are employed, and its best you get good looking females in because that's how sales are going to go up. (Participant 10)

It was found that the influence of heterosexual discourse influenced the misogynistic practices of informal networks in the sexualisation of women/participants. Participant 10 referred to the production of a 'pack mentality' or male privilege that was instigated by men in the solidification of their comradery or "we are the boy's attitude" as an excuse for poor behaviours. This was an example of larger structural issues prevalent in the normalisation of toxic masculinity and exclusion of women in NZ cultures. These circles functioned uninterruptedly, reflected by participant 9 as she described networking to be "significantly more difficult... as a woman". Old boys' networks were the most problematic when companies maintained male dominance at the top of the hierarchy and were especially powerful amongst investors.

Clevenger and Singh's (2013) study of 150 employed workers in the U.S hospitality/tourism industry found that $74 \%$ of participants strongly agreed that qualified women were not moving into senior management positions, indicating the appearance of the old boys network. Although the researchers did not utilise exploratory methods of inquiry, it is interesting to speculate that the general perspectives of women's inability to challenge male networks in international hospitality settings is also reflected in the present findings. This was evident in participant descriptions of an unchallenged status quo, of which physical and immaterial privileges predominately satisfied top tier stakeholders in organisations (Clevenger \& Singh, 2013). The influence of sexuality was also a persistent theme, with "old sleazy males" substantiating the difficulty to disrupt the multidimensional nature of old boys' networks. Participants highlighted practices that upheld exclusionary measures, such as discrediting, harassment and sexualising 
women as the 'other' and object in their employment (Connell \& Messerschmidt, 2005; Mulvey, 1975). Thus, it was evident that female managers had to negotiate with both the law and recreational activities of these privileged groups, unable to satisfy both to an adequate standard due to external influences. Therefore, a gender hierarchy was increasingly visible due to dominant male collectives that had extensive authority in conditioning gendered dynamics of power within the organisation.

\subsection{Communication Networks}

Participants described the manipulation of communication lines as a function of male networking. Exclusion from integral information and business decisions effected female duty managers by impeding communications with staff and disrupting daily operations. Issues with communication were demonstrated by 12 participants in current or previous work. This was exhibited by one manager experience in her $2 \mathrm{IC}$ role:

In regards to communication there is definitely a hierarchy of it being the owner, and then the four GMs... 2ICs don't get taken to those meetings. Then everything gets fed back down. I am not a part of any official management meetings...

I also feel that they could take on more knowledge from a wider base of people, but they choose not to, because of the hierarchy situation that they are in... we call it 'boys club', because that's how it does feel... some of them definitely hangout after the meetings, a few of them will go for drinks... they obviously hang out, they will finish work and go meet up with each other. (Participant 10)

A focal point for participants reflected in the above examples was the gatekeeping of integral business information according to hierarchical male structures. It was found that the most dominant exclusionary cultures existed when upper management circles were predominately male, even when participants had attained a high position in the business. This was reflected in multiple accounts: "I know that the three of them- the bar manager, restaurant manager and owner have weekly meetings but myself as *the only other legal manager does not get invited to these meetings."(Participant 5). And further "they'd [upper management] definitely have conversations during work which I was not privy to which meant that I was the last to find out about a lot of decisions that affected me the most" (Participant 4).These networks were especially detrimental for participants who could not garner important information for general operations, as it decreased potential avenues for new knowledge or proposing ideas as business leaders. It was found that these meetings were often supplemented by recreational activities, which indicated that opportunities for women to network were further minimised. The exclusion of information was performed to extreme extents, depicted in descriptions of the COVID-19 crisis below:

Yeah, it definitely felt like that this week obviously with the whole COVID-19 lockdown and stuff, I was just as in the dark as the rest of the staff members. And people were coming to me and asking what we were doing, what the plan of attack is, how we were going to close down, if we had applied for the wage subsidy, and I said look I actually know as much as you guys do, nobody has told me anything. But the three of them had obviously come up with some sort of plan of attack. I wasn't included. (Participant 5) 
At the current job with the situation that's happening at the moment [COVID-19] there was a manager meeting and I just didn't even get put in the email to come to it. I was the only female manager on the floor at the time with the other guy managers... but there were only specific managers that got invited to the meeting. I am still managing throughout the week, I'm still speaking with customers and staff regularly with no information. It is very concerning. (Participant 8)

These examples portrayed how exclusion from pivotal information was practiced at a crucial time for collective cooperation against uncertainty, ensuring participants were secondary to privileged networks even during a life changing event. It was made explicit that the severity of the COVID-19 health crisis required higher levels of organisational support for employees, however some participants in a managerial position were unable to provide sympathy or guidance to staff due to the evasion of shared information regarding the altered operations of the business. This resistance to gendered inclusivity was also described in generally in daily operations:

I have proposed ideas even myself, in a higher position. And these ideas are not heard...it is a very negative environment. There is no reward system. If you fuck up, you are chastised and beaten down. If you are in the right, hit all of your targets or your staff are doing well, or you are getting good reviews, it is not looked upon favourably. You are not told that you were doing a good job. You are not given any reinforcement that you are doing what you are supposed to be doing. (Participant 7)

I do find with that resistance you can have good ideas as a female in management (which is especially something I've been dealing with quite recently), when you try to make things different or more exciting rather than just the same old same old- there's obviously that resistance of 'oh no I don't want to rock the boat, all of our customers are regulars, if we rock the boat everyone is going to leave'. And I say well if we don't rock the boat, things aren't going to move, we aren't going to go upwards, things are just going to stay as they are. There is that resistance there. (Participant 1)

Participants 1 and 7 outlined the marked resistance to the production and contribution of new ideas or valid working contributions to the business by senior management teams. It was found that prejudice was manifested through negative reinforcement, with women's progression becoming hindered by a culture of misogyny. Communication was experienced as a mechanism that exclusively privileged men who were privy to final decisions in the hospitality organisation. A deficit in full disclosure functioned as a detriment to workplace environments, and impacted employees' ability to perform at full capacity.

Male networks at the peak of the hierarchy utilised a deficit in communication with employees as a manipulative tool, thus substantiating a discourse of resistance to female leaders (Pleasants, 2011). Consistent with existing empirical literature focused on male management teams, it was evident that men in senior positions of the hospitality industry could retain a consistent privileged position in utlising visible techniques of exclusion (Mooney \& Ryan, 2009; Wahl, 2011). This generated an operational disadvantage for employees, distinctly detrimental in times of crisis. Dowling (2003) found that in hotel environments, organisations who view employees as transitionary or unimportant demonstrate a lack of overall investment in staff. Upon further speculation, this finding was relational to the restaurant/bar settings under discussion, as minimal investment in female managers participation problematized their position of leadership, rendering them unavailable to communicate information, planning or 
performance targets. Therefore, deficiencies in communication were portrayed as tactics for male stakeholders to direct and control the gendered dynamic of information exchange, thereby structuring and maintaining exclusionary practices.

\section{3: The Masculine: Perceptions of Exclusion}

The previous findings have highlighted senior management teams as the most consequential contributors to the preservation of the status quo in their access to critical decision-making, and information in organisations. However, exclusion was initiated through the adoption of unprofessional behaviours. Nearly all participants described men with traditionally 'feminine' characteristics in their responses to daily issues. Workplace situations were coloured by "emotional", "volatile" and "hot and cold" displays, that demonstrated a further lack of accessibility for women to problem-solve common issues. This was shown in the following:

It definitely does feel like you are walking on eggshells with him around [the restaurant manager], he is very misogynistic, he doesn't think much of women, he is just really, really hard to work with. He has a really authoritarian style of management as well and can be very aggressive. He can also be very hot and cold...

you do have to kind of feel him out [the owner]... you know sometimes he might sit down with you in the office and have a chat about your day and what's going on, and other times he won't give a rat's ass about what is going on, he's very hot and cold. (Participant 5)

In the traditional sense of biological gender-related attributes, men were effectively described with adjectives that are generally socially pertained to women. This was a key finding in the data as participants actively reduced the appearance of stereotypes, whilst male owners supported them with old boy's networks and male-centric cultures. This was explained further by participant 13, with her experience of an owner that "would yell at you over the smallest things... he would just rip you apart, and you felt broken inside- that is the way he dealt with everything". And further where she had "known the bar manager for years" and found them "crying on the floor" after they had been yelled at by the same man. In a similar vein, participant 4 illustrated that a male GM "was reluctant to teach me anything, and yelled at me, and swore at me in front of customers which made me feel very small". This finding not only transcended the notion of gendered attributes as stagnant, but further provided insight into the communications on behalf of those at the top of the hierarchy. Participants described the blatant misuse of power as unnecessary experiences in which productivity could be better stimulated by direct, unemotional communications that were not influenced by personal problems or prejudice. For example:

No one feels comfortable... I know for me when he gives it out, I'm more likely to clap back, but we work with a lot of young women... who maybe don't have the confidence to speak up as much as myself. (Participant 5)

One of the managers was gay, and because he was a flamboyant natured man, *the business owner took ill upon him as well... our old restaurant manager *Katy was a prime example of [workplace] bullying and suppressing her opinion, it was horrible to witness actually. But that is what *the business owner is really like. (Participant 7) 
I have had quite a few altercations with the GM's that I have worked for... I have had multiple instances where I've been in his office, and I have come out crying... I did feel that one of the managers that I worked with used quite a lot of bully tactics. (Participant 2)

Participants described unprovoked bullying and harassment in conjunction with common descriptions of emotionality/volatility when communicating with senior management. This discrimination provided a distinct barrier to the improvement of workplace environments and were significantly unethical- accentuated by participant 7's experience of homophobia and misogyny. It was evident that some participants refused to accept such conditions, notable in participant 5's account and further with "they [business owners] think 'I can just run it however I want' and that's actually not acceptable anymore" (Participant 10). However, the majority of participants were unable to negate the effects of toxic environments, surmised by participant 2 where she had "come out crying" as a result of these behaviours.

Persisting detrimental male corporate cultures have been uncovered as a main pillar in the glass ceiling effect across international hospitality and tourism settings (Carvalho, et al., 2018). Previous empirical research has underlined men's negative attitudes towards women in the organisation (Dubno, 1985), despite changing discourses surrounding equality and gendered workplace structures, of which was reflected in the current findings (Carvalho, et al., 2018). The research demonstrated the preservation of womens submission, initiated by male socioemotional reconfigurations of power-dominance tactics (Hearn \& Parkin, 2007). This provided an interesting perspective for the development and enactment of gender stereotypes/attributes. Inconsistent with previous sex-stereotyping research (Eagly \& Karau, 2002), it was clear from the current findings that either feminising or masculinising leadership styles was in fact, a biological fallacy. In reality, leadership was redefined by senior men as individual 'performers' inside of organisational business roles (Butler, 1988), with their actions/behaviours informing participant perspectives. It was evident however, that toxic masculinities were generated from the organisation of detrimental working relationships, seen clearly in the manipulation of socioemotional relations to enforce higher levels of percieved authority (such as bullying).

\section{Finding 4: Professional Development}

Training/professional development was a focal point for all 13 participants, with only one manager receiving on-site, regular managerial training after obtaining her formal duty manager's certificate from the local council. All participants expressed there was minimal difficulty in obtaining both their LCQ and subsequent DM's licence. No participants identified any formal feedback after obtaining their qualifications and initially performing as a manager without supervision in the first year, this included: no visits from local council, authorities, or within-business reviews. Participant 9 received ongoing support but did not indicate the level of formal feedback received. The main focus for participants in this section was the identification of improvements to current practice in the hospitality industry in order to retain staff on a long-term basis. All participants discussed both advantages to business practices they had experienced in NZ, and further the disadvantages of larger socio-cultural systemic issues that resided in the undercurrent of misogynistic attitudes and stereotypical notions of leadership. Participants expressed that a balance of gender in organisational teams was the most advantageous for the business dynamic, due to an accessibility to a wide range of skillsets and perspectives to support both staff and customers. 


\section{1: Female Support}

Mentors/role models were accentuated by participants as key contributors to their success due to the support and training they had received on site from these individuals. All participants could identify a mentor that they had learnt imperative skills from early in their careers. These mentors were relatively balanced by gender, however all participants adamantly pointed out the advantages of having a female authority figure in the industry of which they modelled their leadership skills from. Participants illustrated their professional development stimulated by mentors in the building of strategies to negate the effects of discrimination. They also described learning ways in which they could support future teams of female staff when dealing with sensitive situations that were experienced by women differently in the hospitality industry.

Participant 9 who was employed in an LGBTQ+ venue highlighted her struggle without an immediate female role model exemplified in the following: "I had a really good relationship with [the GM] but there were definitely things that affected my ability to do my job that he wouldn't understand and therefore couldn't help me with". The GM in context was unable to provide guidance in negotiating misogyny, and therefore could not provide participant 9 with appropriate response techniques for the different negative social reactions to female leaders in the industry on behalf of colleagues and customers. It was evident that female to female support networks in either mentorship or professional friendship were imperative to participants professional/personal success in navigating gendered issues discussed in the previous sections of the findings chapter, of which was exemplified in the following: "she was great. She really, really was and we very much worked as a team together. She was very supportive and she kind of understood that being female it was a very different situation" (Participant 10). Another respondent explained "she was a really good person to learn from because she had a lot of the same personality traits as me in terms of prioritising people's wellbeing and making sure everyone was being heard" (Participant 3).

A focal point for participants was discovering or receiving socio-emotional support from women in leadership that could not be performed by men to the same degree. In the above examples, both participant 10 and 3 immediately changed their tone of voice with a noticeable excitability linked to admiration when they discussed their female colleagues. Participant 12 further emphasised that "supporting strong females coming through and allowing them to support each generation that comes through ... is super important". Participants demonstrated that support was not an inherently 'feminine' attribute however, as a selection of participants also described positive experiences with male managers. Yet in the above illustrations, relationships were built from a mutual understanding of gender-based oppressions. Participants realistic, gendered perspectives of the industry through a collection of experiences meant that female-female industry peers could relate to each other on a personal, supportive bases. This was demonstrated in the following insights: "women have really important insight I think to how the world works, and this might be playing on feminine traits here, but I think that women have something different to bring to the table than maybe men do" (Participant 5). "Fitting into the team is more important than asserting your leadership style... that's where I think female managers come into play a lot, we have a lot more usable empathy. And that's what makes female managers very special and effective" (Participant 6).

It was found that 'feminine traits' traditionally viewed negatively by men in the organisation were celebrated by women in their holistic perspective of staff and daily situations, making them "important", "special" and "effective". All 13 participants placed a huge importance on interpersonal relationships rather than adopting a neoliberal rhetoric of individualisation in 
hospitality environments. Participants emphasised their organisation of collective teamwork and collaboration, and professionally placed others needs/happiness before their own. For example: "I want to take everyone's considerations into account" (Participant 8). Another illustrated "I'm quite a personal person, I do take into consideration what everyone else feels" (Participant 2). And in even in the experience of a non-heteronormative venue: "I think my style of management now is mostly a 'lead from behind' approach, I prefer to be one of the team" (Participant 9). Therefore, a focal point for all participants was the ethical/moral concerns of daily practice as leaders. Leadership styles were described to be approachable, cooperative, and understanding of both personal and professional issues that occurred for staff in the organisation. This was highlighted in conjunction with the frequently used term of "assertive", of which participants used as a tool to adjust personal perceptions of gender conformity. Although all participants faced intersectional barriers cross-organisationally, they described facing problematic issues with agency whilst upholding professionality and strong personal values. For example, in participant 3's description: "I used [supporting others] as a coping mechanism ...to make people feel as valued as possible" when she described dealing with bulling/harassment from a male colleague.

The majority of participants expressed their ethical concerns in protecting staff, especially younger women, from broader organisational and socio-cultural issues that were normalised in the industry, such sexual harassment. This was further highlighted by participant 7 in discussing sexual assault: "If anyone came to me and explained a similar situation, I would be totally on board with protecting them". This was especially potent in participant 7's experience, in light of her previously discussed sexual assault in the workplace. She explained comically with a laugh that "I don't give a shit... nobody decided to grab your balls!" in commenting on the normalisation of sexual harassment. Participants navigated detrimental situations in their demonstration of unwavering support for their teams of staff, even when they had received none themselves in organisations.

Previous research has indicated the importance of female-female mentoring dyads due to their success in developing skillsets that aid in organisational advancement and high levels of socioemotional support (Headlam-Wells, et al., 2005; Leck et al., 2012). This was especially prevalent in the hospitality industry, wherein additional variables such as intoxication and harrassment meant that the negotiation of problematic circumstances had to be approached differently by female participants. In line with Carless (1998) study of female managers, the current findings highighted the importance women placed on collaboration in group settings as a form of transformational leadership inspired by collective participation and support. Although communal behaviour was prefered by participants, their leadership behaviours were not described as essentially different to their male counterparts but rather more inclusive. It was therefore clear that men were more individuated in their actions, behaviours and attitudes due to their assumed power at the top of the hierarchy (Ragins, Townsend \& Mattis, 1998), whereas women formed a collective interdependant of all employees (Cross \& Madson, 1997). An important insight to these findings was that transformational styles of leadership were not inherently gendered and could be performed by both men and women. However, it was clear that female managers were influenced by gendered socialisation in their enactment of personal values and role-modelling behaviours.

\subsection{Career Trajectory}

Participants described their frustrations with the lack of clarity surrounding career trajectories, illuminated in the absence of organisational action towards contractual obligations such as 
performance reviews. This was also found to be problematic for lower-level staff due to a described lack of formalisation in workplace professional training:

There were two or three newer managers that didn't have anything nice to say- and they had gone from waitress or waiter to manager. I would check on them every now and again, and they would still be unhappy as they weren't getting any time for development, they were working ridiculous hours because there's no staff. (Participant 2)

So you don't have any formal job chats to base your performance of off, you don't have any formal development or training either... from what I have seen of the younger managers as well... if they haven't had training it can be really, really hard- dealing with intoxication in old people when you are a young person- they actually aren't trained for those situations, they are kind of just dumped in it and they are expected to run. (Participant 10)

It was found at all levels in hierarchy that organisational support for professional development was minimised by business' short-term emphasis on profitability rather than investment in staff. This mirrored the previously discussed lack of support for participants when initially gaining qualifications in section 2.1. Participant 10 accentuated the serious consequences associated with minimal training on-site, as legal issues under liquor licensing was not limited to theoretical knowledge and required practical experience. Participant 6 reflected further that "even in small businesses, they aren't putting enough emphasis on proper training, like a signed off training". Participant 5 also stated that "training for all staff... and managers is pretty minimal". Therefore, participants emphasised that organisational support for staff was minimised due to a lack of recorded training modules, meaning that their progression was not formalised. This was further reflected in participant 8's personal account:

It's more like you get to a stage where progression just stops. Communication is a big one, your voice needs to be heard regardless of whether someone is listening or not, at the end of the day it's about doing things for yourself. (Participant 8)

The lack of formal development and investment in employees was internalised by participants as an obstacle that they had to personally overcome in developing opportunities and a "voice" against dominant organisational cultures. Participant 13 reflected similar sentiments, with: " $m y$ biggest comment would be, don't be quiet because they aren't there to listen to you. That was my biggest downfall as a manager." The majority of participants therefore expressed their own sense of agency by including themselves in conversations for progression, even when purposefully excluded. The theme of "doing it for yourself" reflected a lack of change and resistance to investment in female managers.

The findings echoed Ragins et al., (1998) study wherein female participants reported taking on personal responsibility to seek out professional development through challenges/assignments in order to formally record success. Participants in the current research had to work to overcome the intersectional nature of the glass ceiling in the industry without professional support, reflected by participant 4's biggest obstacle in her career being "that I am a woman". Having a "voice" for change was a common theme against the oppression of a masculinised status quo. Under speculation, previous research that has underlined women's lack of career development as a self-imposed issue was clearly unsupported by the current findings (Boone, et al., 2013; Brizendine, 2008; Fischlmayr, 2002). These studies highlighted a failure to recognise the wider 
set of conditions that structure the hospitality sector in its characteristically gendered environment (Wahl, 1992) and relative deficiency in supporting female leaders (Carvalho, et al., 2018). The discernable insufficiency of women succeeding at executive levels in the industry is therefore apparent in a lack of formalised training/professional review, and absence of support from both the organisation and wider authorities for the betterment of all practitioners, regardless of gender.

\subsection{Pay Equity}

In the previous section, participants had identified their personal responsibility to seek success and professional development, of which was unincentivized by a reflection in pay rates. This introduced another barrier in which women could not seek support from colleagues, due to perceptions of confidentiality stipulations in their contracts: formal discussions regarding pay and performance were only contractually viable from owner to participant. Participants risked disciplinary action or loss of their position if these matters were discussed freely with other members of the industry.

Participants described a culture in which they were actively discouraged or felt uncomfortable discussing remuneration, even when they had performed well over a long period of service in an organisation. This was especially difficult for participants who described their work in smaller-scale businesses, as the costs of operations appeared to be higher, rather than shared across multiple sites. Participants expressed frustration with both a lack of pay equity and opportunities to stimulate open discussions against their professional development, for example:

What gives me huge anxiety is asking for a pay rise. I can't do it. I think on your contract it says three monthly appraisals, but I will be honest with you not a lot of hospitality businesses follow that. (Participant 4)

Women have an issue with talking about money and pay rises... it is hard, you have to prove your worth, you have to discuss what is happening in the country, or example living wage is going up, and minimum wage comes up as well- is there a trajectory to keep your wage rising alongside it as well, because then you'll have more skill but you aren't necessarily being paid for it. (Participant 6)

Participants highlighted that a barrier to pay rises existed, due to the minimisation of accessibility to even-grounded communications based on both skill set and position. A definitive grey area across the industry was a focal point for participants who expressed that pay rates were extremely variable and often gendered across organisations. It was not necessarily skill set or proven professional development that were described as the main factors that contributed to levels of renumeration, elucidated below:

Pay rate is another one, I feel that everyone should be equal, but they are obviously not. So we have a male GM, and two other male managers at the moment and all of them are getting paid more than me, a couple of dollars more... we all work full time, work 40-50 hours a week, we have the same responsibility. What's the difference? (Participant 8)

There is no set pay scheme- for example you don't necessarily know compared to anyone else what you should be on.... so, it's quite hard to regulate whether people are 
being underpaid, overpaid, paid fairly, and getting paid the same as colleagues. (Participant 10)

It was clear that in participant 8's case, inequalities were reflected in gendered pay rates for identical management positions. She explained that every female manager in her organisation resigned at the time of the interview, and "are all leaving because we all feel the same. We are not treated equally or supported" of which she expressed with extreme disappointment. Another 8 participants described a heightened difficultly with the experience of inequalities associated with misogynistic cultures and felt as though resignation was the most productive action forward to progress in the industry in previous or current positions. An undercurrent of perceived underappreciation/unfairness was cultivated across accounts, for example participant 7 expressed "I do find myself taking on more responsibilities than I should be, and not being paidfor it or appreciated". The lack of regulation surrounding remunerations was also clarified by another respondent: "it's a difficult one, I think it would be up to business owners to be more honest and to have community conversations about it" (Participant 10). Pay rates were therefore problematized due to differing situations reliant on scale/size of the business, accessibility to performance reviews and gendered variables based on organisational cultures.

The hospitality industry is highly feminised with a higher participation rate of women in lower positions of the hierarchy, yet distinguished by the concentration of the masculine in senior leadership positions who maintain the ability to organise employees and determine renumerations (Perez, et al., 2019). It was evident in the findings that misogynistic gendered structures determined the production of inequalities between roles in hierarchies, with women's renumerations minimal even when performing in the same positions as men. Therefore, the differences in gendered responsibilities and lack of contractual stimulation accentuated the appearance of a wage gap between male and female employees (Perez, et al., 2019). This is further reflected in present statistics that indicate the persistence of an international wage gap despite the participation of women in the workforce, with a median of $13.4 \%$ across OECD countries (Catalyst, 2020). This was discussed by participant 8 , who could not achieve the same pay rate as her male counterparts despite having the same contractual responsibilities. Although participants were made personally responsible for their own career progression consistent with previous empirical research (Pizam, 2017), it was significant that they maintained relative agency in choosing to resign if they could not achieve better working conditions/pay rates. This meant that they still maintained a level of empowerment in their employment, however it was not clear if organisational practices improved after they left. 


\section{Final Reflection}

The findings of the current study have been discussed in alignment with social theory and previous empirical research. The Wellington, NZ hospitality industry shared a plethora of characteristics that formed a glass ceiling cross-organisationally. However, the construction of gendered barriers was ultimately unique to the localised bar/café/restaurant cultures, and subsequently operated on multi-faceted levels. All participants experienced different layers of oppression of which can be summarised in the formulated diagram below:

\section{Top-Down Effect: The Hospitality Organisation}
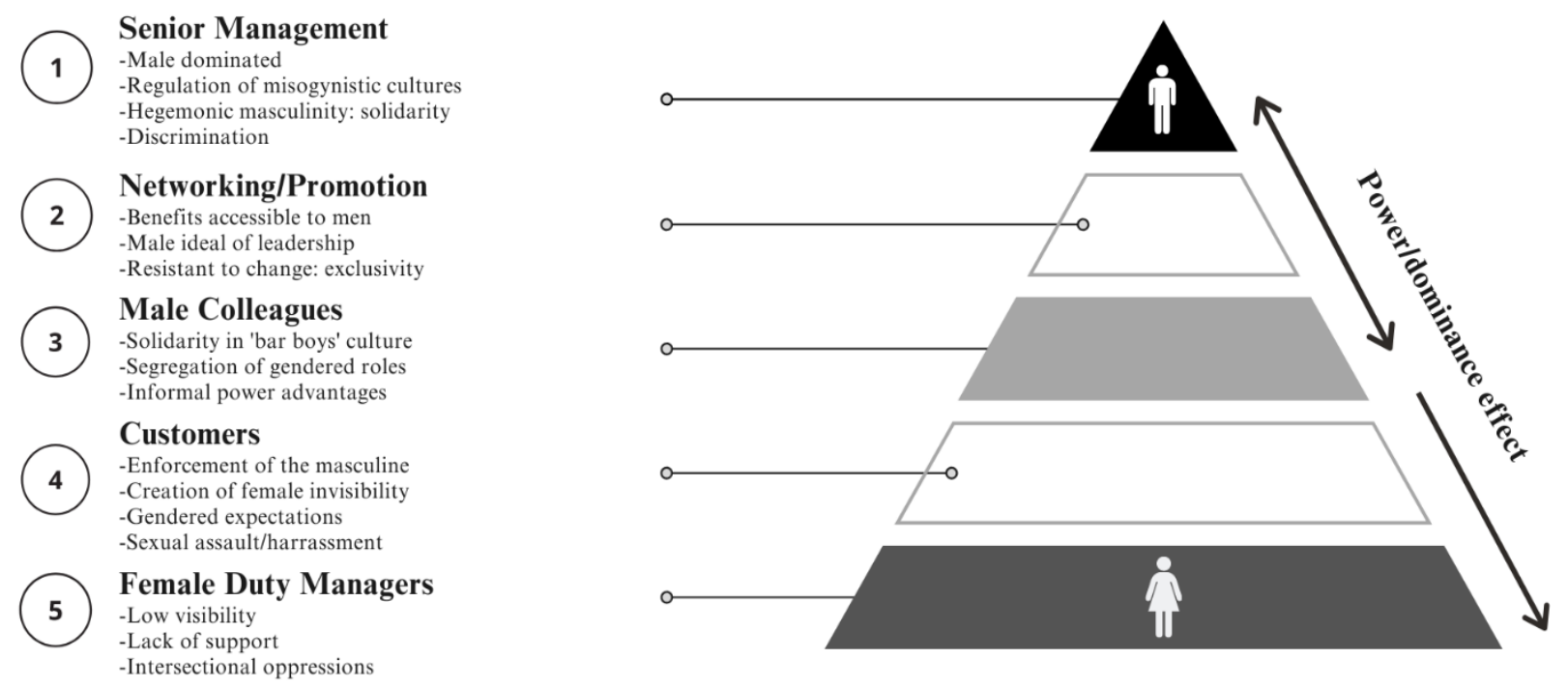

Figure 1. Top-Down Effect: The Hospitality Organisation

The diagram portrays the "top down" hierarchical construction of male dominance in the industry, interweaving a relationship of power and submission on five main levels. The illustration conveys how the patriarchal unconscious operated at the top four levels to sustain the status quo and resistance to female leaders in the industry. The absence of interaction for women at the bottom of the social scale represented their minimised ability to challenge or influence the solidification of male power. This diagram demonstrated a localised scale of which was experienced by the majority of participants working in heteronormative venues that were operated by male-centric senior management teams. One of the key findings in the research was that the creation of misogynistic cultures relied on those who participated, and therefore received the benefits from their normalisation. The findings suggest that an interruption to any conditions stated under all 5 levels in figure. 1 could invigorate change, yet the most influential innovators to equitable cultures still resided with men at the top tier.

The main findings depicted four main barriers to women's career development in the industry, from gender-stereotyping/misogyny on intersectional levels, to a deficit in advancement and 
professional development, and further an emphasis on women's exclusion through old boys' networks. These factors were integral to the development and maintenance of the glass ceiling for female managers in the localised hospitality industry, reflected in figure 1 . However, it was clear that all participants were able to develop individual agency against these oppressions through enacting transformative leadership styles, collaborating with other female leaders for support and developing their own goals for success. The regulation of larger structural, cultural and social beliefs surrounding the interplay of gender and leadership was continuously interrupted by the participants in their negation of stereotypes and importance placed on their personal success and wellbeing, even if challenges to industry norms remained difficult. This was identified in their refusal to accept detrimental treatment and maintaining the female 'voice' as an overlooked source of power and difference to the male norm. Although the perception and assumptions surrounding gender in the social sphere of the hospitality industry worked against participants general operations, they were eager to demonstrate a change in the status quo.

\section{Research Limitations}

The research examined barriers to career development for female managers in the NZ hospitality industry. The participants in the study shared distinct experiences of their personal and professional development based on café, restaurant, and bar environments. However, the study was limited in generalisability due to the small sample size of 13 women focused on experiences in the Wellington, NZ region. The insights that were developed throughout the findings did not impact upon credibility, but instead provided a detailed collection of local socio-structural organisational cultures. In utilising a feminist approach, participant verbatim was used to explore the intersectional influences on women's experiences rather than their causality, thereby inviting further examination for future research. Due to the limited scope of the research questions however, further intersectional analyses focused on the multitude of elements contributing to women's oppression could not be explored in depth, such as the role of ethnicity, sexuality, race and disabilities. To provide an increasingly nuanced and reflective perspective of women's experiences in the industry, it would be advantageous to incorporate a larger sample size inclusive of these components.

Furthermore, the findings were predominately reflective of female managers experiences in heteronormative venues. Participant 9's experience of an LGBTQ+ environment clarified that workplaces cultures contributing to the glass ceiling were developed according to the level of conformity to the male norms and exclusionary practices. It should be noted for future research that studies involving queer organisational environments may involve alternative and distinguished social nuances that could not be explored in in the current findings. This could produce a challenge to normative discourse surrounding the role of (hetero)sexuality and gender in the workplace. Moreover, the participant data was impacted by the psychological impact of the COVID-19 health crisis. The findings were predominantly reflective of experiences in the industry before the occurrence of a nationwide lockdown, of which has now limited hospitality operations long term. This should be considered if the research is reviewed in conjunction with future economic and social trends. Lastly, feminist researchers should be acutely aware of potential bias and existing oppressions. Researcher bias was countered to an extent by maintaining a necessary social consciousness in privileging the voices of female participants, whilst balancing a personal understanding of shared and common experiences objectively.

Research Recommendations and Beyond 
Improvements based on the limited scope of the current research findings were developed in accordance with localised industry characteristics. In reference to figure 1, the findings suggested that an interruption of normalised beliefs surrounding gender in leadership was required on behalf of men in the organisation to simultaneously provide a level of inclusivity and higher level of visibility for female managers. This could be organised through gender equality initiatives on behalf of the business, to challenge complicit masculinities and invigorate a change in practice. Based on the findings and existing associated literature, initiatives could include:

1. Zero tolerance policies for management teams dealing with sexual harassment at all levels. Prevention/intervention training mandatory for all managers every 12 months.

2. Diversify employee skillsets with the introduction of competency requirements for both floor and bar (interruption of gender segregation).

3. Responsibility for advancement deferred from the individual to the organisation through equality policies that encourage the promotion/retention of female employees (Ferguson, 2009).

4. Team-building events created every 3-6 months to promote internal networking that include senior management teams, as an investment in staff as a collective.

5. Examination of workplace cultures in management teams to understand factors contributing to prejudice/misogyny. Development of practical changes thereafter unique to the organisation (Clevenger \& Singh, 2013).

6. Adherence to contractual stipulations regulated by a senior delegate (3-month performance reviews, pay reviews). Stimulation of career trajectories.

7. Counselling/mental health services made accessible within the organisation through well-being initiatives and paid for by the organisation for work related incidents.

8. Larger structural regulation of discrimination: external reviews of equality policy initiatives for businesses from authorities (city council/police).

9. Culture of listening stimulated through weekly meetings that are mediated by senior management and primarily led by management teams.

The research further suggests that promotional opportunities should be made available to all individuals in management teams synchronously for unbiased communications and an equitable chance to succeed, as suggested by Clevenger and Singh (2013). To ensure impartiality, the formalisation of progression would be required in the form of a common written module/record that is identical for all managers to fairly review both employee growth and potential deficits in performance. In this light, business productivity would become transparent for company stakeholders and could escalate both employee retention and advancement incentives. The measurement and oversight of professional development should be peer-reviewed or approached collectively to minimise male networking privileges and gender bias.

For heteronormative venues, the findings highlighted the positive impact of female support or role modelling on participants employment. It is therefore suggested that a senior female employee could be delegated to an advocate role to ensure contractual stipulations are actioned in detrimental circumstances for all employees regardless of gender. This would have the doubled effect of introducing an opportunity for promotion and stimulate the ability for senior management teams to plan an appropriate course of action forward in-house. Thus, the position would indirectly generate a strengthened support network and allow for employees to openly express concerns without navigating the power-driven negligence produced by those at the top of the hierarchy. This would therefore effectively restructure the 'old boys' network however 
would be reliant on the production of a newly delegated culture of listening and willingness of the organisation to carry out ethical and substantial mediation in accordance with the advocate role.

\section{Conclusion}

The research has examined the primary exploration of female duty managers career advancement specific to bar, restaurant, and café environments in the context of the NZ hospitality industry. The investigation has provided an in-depth response to the initial research aims by exploring the socio-cultural construction of glass ceiling barriers for participants in a localised environment, of which were revealed as multi-layered oppressions on industry, customer, and organisational levels. An identification of industry and business level improvements have been outlined for the betterment of women's current working conditions. Although the women in this study had attained a duty managers position, their experiences of misogyny, discrimination and exclusion were most prevalent in their interactions with senior men in organisational hierarchies at the management level. This meant that their leadership potential and performance was often rendered invisible due to the gendered structure of organisations. The industry therefore remains highly gendered in nature, upheld by the patriarchal unconscious and regulation of hegemonic masculinities in networking circles. The women in this study were forced to navigate misogyny and gendered expectations in the workplace with resistance to their advancement. This was reinforced by wider structural and socio-cultural beliefs surrounding gender in leadership and the generalised oppression of women participating in the workforce. Therefore, an awareness of inequalities must be stimulated cross-organisationally to re-examine the protection of male privilege in senior management teams. The power for positive social change through equality initiatives reside in the actions of men in both the organisation and wider society. 


\section{References}

Acker, J. (1990). Hierarchies, jobs, bodies: a theory of gendered organisations. Gender \& Society, 4(2), 139-158. Retrieved from http://www.jstor.org/stable/189609

Acker, J. (2006). Inequality regimes: gender, class and race in organisations. Gender \& Society, 20(4), 441-464. https://doi.org/10.1177/0891243206289499

Acker, J., Barry, K., \& Esseveld, J. (1983). Objectivity and truth: problems in doing feminist research. Women's Studies International Forum, 6(4), 423-435. https://doi.org/10.1016/0277-5395(83)90035-3

Adams, E. G. (1978). A multivariate study of subordinate perceptions of and attitudes toward minority and majority managers. Journal of Applied Psychology, 63(3), 277-288. https://doi.org/10.1037/0021-9010.63.3.277

Allen, T., Eby, L., Poteet, M., Lentz, E., \& Lima, L. (2004). Career benefits associated with mentoring for proteges: a meta-analysis. Journal of Applied Psychology, 89(1),127136. https://doi/org/10.1037/0021-9010.89.7.127

Amaratunga, D., Haigh, R., Shanmugam, M. L., \& Elvitigala, G. (2006). Construction industry and women: a review of the barriers. Proceedings of the 3rd International SCRI Research Symposium. Delft. Retrieved from http://usir.salford.ac.uk/9877/

Bartky, S. (1997). Foucault, femininity and the modernization of patriarchal power . In K. Conboy, N. Medina, \& S. Stanbury (Eds.), Writing on the body: female embodiment and feminist theory (pp. 129-154). New York: Columbia University Press.

Bartol, K. (1978). The sex structure of organisations: a search for possible causes. Academy of Management Review, 3(4), 805-881. Retrieved from https://search-proquestcom.helicon.vuw.ac.nz/docview/230027130/fulltextPDF/83D64A2DDDB54B44PQ/1 ?accountid $=14782$

Bartol, K., \& Martin, D. C. (1986). Women and men in task groups. In R. D. Ashmore, \& F. K. Del Boca (Eds.), The social psychology of male-female relations (pp. 259-310). New York: Academic Press.

Bartol, K., Martin, D. C., \& Kromlowski, A. (2003). Leadership and the glass ceiling: gender and ethnic group influences on leader behaviours at middle and executive managerial levels. Journal of Leadership and Organisational Studies, 9(3), 8-19. https://doiorg.helicon.vuw.ac.nz/10.1177/107179190300900303

Bartram, S. (2005). What is wrong with current approaches to management development in relation to women in management roles? Women in Management Review, 20(2), 107 116. https://doi-org.helicon.vuw.ac.nz/10.1108/09649420510584445 
Baumgartner, S., \& Schneider, D. (2010). Perceptions of women in management: a thematic analysis of razing the glass ceiling. Journal of Career Development, 37(2), 559-576. https://doi.org/10.1177/0894845309352242

Benschop, Y., \& Doorewaard, H. (1998). Covered by equality: the gender subtext of organizations. Organization Studies, 19(5), 787-805. https://doi.org/10.1177/017084069801900504

Boone, J., Veller, T., Nikolaeva, K., Keith, M., Kefgen, K., \& Houran, J. (2013). Rethinking the glass ceiling in the hospitality industry. Cornell Hospitality Quarterly, 54(3), 230239. https://doi.org/10.1177/938965513492624

Braun, V., \& Clarke, V. (2006). Using thematic analysis in psychology. Qualitative Research in Psychology, 3(2), 77-101. https://doi.org/10.1191/1478088706qp063oa

Braun, V., \& Clarke, V. (2012). Thematic analysis. In H. Cooper, P. M. Camic, D. Long, A. Panter, \& D. Rindskopf (Eds.), APA handbook of research methods in psychology, vol 2: research designs: quantitative, qualitative, neuropsychological and biological (pp. 57-71). Washington, DC: American Psychological Association. https://doi.org/10.1037/13620-004

Braun, V., \& Clarke, V. (2013). Successful qualitative research: a practical guide for beginners. United Kingdom: SAGE Publications Ltd.

Brickell, C. (2009). Sexuality and dimensions of power. Sexuality \& Culture, 13(2), 57-74. https://doi.org/10.1007/s12119-008-9042-x

Brizendine, L. (2008). One reason why women don't make it to the C-suite. Harvard Business Review, 86(6), 36. Retrieved from http://web.b.ebscohost.com.helicon.vuw.ac.nz/ehost/pdfviewer/pdfviewer?vid=0\&sid $=80013 \mathrm{ac} 2-2 \mathrm{~b} 69-4 \mathrm{e} 1 \mathrm{f}-9451-\mathrm{cf} 760 \mathrm{~d} 97 \mathrm{e} 5 \mathrm{e} 2 \% 40 \mathrm{pdc}-\mathrm{v}-\mathrm{sessmgr06}$

Broadbridge, A., \& Hearn, J. (2008). Gender and management: new directions in research and continuing patterns in practice. British Journal of Management, 19(1), 38-49. https://doi.org/10.1111/j.1467-8551.2008.00570.x

Brown, G., Western, D., \& Pascal, J. (2013). Using the f-word: feminist epistemologies and postgraduate research. Journal of Women and Social Work, 28(4), 440-450. https://doi-org.helicon.vuw.ac.nz/10.1177/0886109913503266

Butler, J. (1986). Sex and gender in Simone de Beauvoir's Second Sex. Yale French Studies, 72, 35-49. https://doi.org/10.2307/2930225

Butler, J. (1988). Peformative acts and gender constitution: an essay in phenomenology and feminist theory. Theatre Journal, 40(4), 519-531. https://doi.org/10.2307/3207893

Carbey, R., Garavan, T. N., O'Brien, F., \& McDonnell, J. (2003). Predicting hotel managers' turnover cognitions. Journal of Managerial Psychology, 18(7), 649-679. https://doi.org/10.1108/02683940310502377 
Carless, S. A. (1998). Gender differences in transformational leadership: an examination of supervisor, leader, and subordinate perspectives. Sex Roles: A Journal of Research, 39(11), 887-902. https://doi.org/10.1023/A:1018880706172

Carvalho, I., Costa, C., Lykke, N., Torres, A., \& Wahl, A. (2018). Women at the top of tourism organisations: views from the glass roof. Journal of Human Resources in Hospitality \& Tourism, 17(4), 397-422. http://doi.org/10.1080/15332845.2018.1449551

Catalyst. (2020, January 15). Pyramid: Women in S\&P 500 Companies. Retrieved from Cataylst: Workplaces that Work for Women: https://www.catalyst.org/research/women-in-sp-500-companies/

Catalyst. (2020, March 2). Quick Take: Women's Earnings- The Pay Gap. Retrieved from Catalyst: Workplaces that Work for Women: https://www.catalyst.org/research/womens-earnings-the-pay-gap/

Charmaz, K. (2014). Writing feminist research. In S. Hesse-Biber (Ed.), Handbook of feminist research: theory and praxis (pp. 475-494). Thousand Oaks: SAGE Publications, Inc.

Chilisa, B., \& Nteane, G. (2010). Resisting dominant discourse: implicationos of indigenous, African feminist theory and methods for gender and education research. Gender and Education, 22(6), 617-632. https://doi.org/10.1080/09540253.2010.519578

Clevenger, L., \& Singh, N. (2013). Exploring barriers that lead to the glass ceiling effect for women in the U.S hospitality industry. Journal of Human Resources in Hospitality and Tourism, 12(4), 376-399. https://doi.org/10.1080/15332845.2013.790258

Collins, P. (2000). Black feminist thought (2nd ed.). New York: Routledge.

Collinson, D. L., \& Hearn, J. (2005). Men and masculinities in work, organisations and management. In M. Kimmel, J. Hearn, \& C. R. W (Eds.), Handbook of studies on men and masculinities (pp. 289-310). CA: Thousand Oaks: Sage.

Collison, D., \& Hearn, J. (1996). Managers as men: critical perspectives on men, masculinities and management. London: Sage.

Connell, R. (2001). The social organization of masculinity. In S. Whitehead, \& F. Barrett (Eds.), The masculinities reader (pp. 30-50). Cambridge: Polity Press.

Connell, R. W. (2000). The men and the boys. Berkley, Los Angeles: University of California Press.

Connell, R. W., \& Messerschmidt, J. W. (2005). Hegemonic masculinity: rethinking the concept. Gender and Society, 19(6), 829-859. https://doi.org/10.1177/0891243205278639

Cotes, E. J., \& Feldman, R. S. (1996). Gender differences in nonverbal correlates of social status. Personality and Social Psychology Bulletin, 22(10), 1014-1022. https://doi.org/10.1177/01461672962210004 
Creswell, J. (2007). Qualitative inquiry and research design: choosing among five approaches. Los Angeles: Sage.

Crosby, F. (1984). The denial of personal discrimination. American Behavioral Scientist, 27(3), 371-386. https://doi.org/10.117/000276484027003008

Cross, S. E., \& Madson, L. (1997). Models of the self: self-constructuals and gender. Psychological Bulletin, 122(1), 5-37. https://doi.org/10.1037/0033-2909.122.1.5

Crotty, M. (1998). The foundations of social research: meaning and perspective in the research process. Thousand Oaks: SAGE Publications.

Dainty, A., Neale, R., \& Bagihole, B. (2000). A grounded theory of women's career under achievement in large UK construction companies. Construction Management and Economics, 18(2), 239-250. https://doi.org/10.1080/014461900370861

Davies, B. (2008). Judith Butler in conversation: analysing the texts and talk of everyday life. New York: Routledge.

Davies, B., Browne, J., Gannon, S., Honan, E., Laws, C., Mueller-Rockstroh, B., \& Bendix Petersen, E. (2004). The ambivalent practices of reflexivity. Qualitative Inquiry, 10(3), 360-390. https://doi-org.helicon.vuw.ac.nz/10.1177/1077800403257638

Dawood, M. (2008). Sampling rare populations. Nurse Researcher, 15(4), 35-41. https://doi.org/10.1002/9781118594629.ch4

DeVault, M. (1990). Talking and listening from women's standpoint: feminist strategies for interviewing and analysis. Social Problems, 37(1), 96-116. https://doi.org/10.2307/800797

DeVault, M., \& Gross, G. (2014). Feminist qualitative interviewing: experience, talk and knowledge. In S. N. Hesse-Biber (Ed.), Handbook of feminist research: theory and practice (pp. 206-236). Thousand Oaks: Sage.

Dowling, S. (2003). Does the glass ceiling exist in hospitality? The Graduate Management Review, 1, 37-42. Retrieved from

https://ndhadeliver.natlib.govt.nz/delivery/DeliveryManagerServlet?dps_pid=FL1621 9247

Dubno, P. (1985). Attitudes toward women executives: a longitudinal approach. Academy of Management Journal, 28(1), 235-239. Retrieved from https://search-proquestcom.helicon.vuw.ac.nz/docview/229540251?rfr_id=info\%3Axri\%2Fsid\%3Aprimo

Eagly, A. H., \& Karau, S. J. (2002). Role Congruity Theory of Prejudice Toward Female Leaders. Psychological Review, 109(3), 573-598. https://doi.org/10.1037/0033/295X.109.3.573

Eagly, A. H., Wood, C., \& Johannesen-Schmidt, M. C. (2004). Social roles theory of sex differences and similarities: implications for the partner preferences of women and men. In A. H. Eagly, A. Beall, \& R. J. Sternberg (Eds.), The pyschology of gender (pp. 269-295). New York: Guilford Press. 
Ehrich, L. (2008). Mentoring and women managers: another look at the field. Gender in Management, 23(7), 469-483. https://doi.org/10.1108/17542410810908839

Employment New Zealand. (2020, April 1). Minimum wage increases from April 12020. Retrieved from Employment New Zealand:

https://www.employment.govt.nz/about/news-and-updates/minimum-wage-increase1-april-2020/

Employment New Zealand. (2020, August 19). Wage Subsidy Schemes. Retrieved from Employment New Zealand: https://www.employment.govt.nz/leave-andholidays/other-types-of-leave/coronavirus-workplace/wagesubsidy/\#: :text=Financial\%20support\%20for\%20businesses\%20and,an\%20income $\% 20$ for\%20affected\%20employees.

Elacqua, T., Beehr, T., Hansen, C., \& Webster, J. (2009). Managers beliefs about the glass ceiling: interpersonal and organisational factors. Psychology of Women Quarterly, 33(3), 285-294. https://doi.org/10.1177/036168430903300304

Esping-Andersen, G. (2005). Final remarks: a jobless and childless Europe? In D. Boeri, D. Boca, \& C. Pissarides (Eds.), Women at work- an economic perspective (pp. 268274). New York: Oxford.

Ferguson, L. (2009). Analysing the gender dimensions of tourism as a development strategy. Madrid: Universidad Complutense de Madrid. Retrieved from https://eprints.ucm.es/10237/1/PP_03-09.pdf

Fischlmayr, I. (2002). Female self-perception as barrier to international careers? International Journal of Human Resource Management, 13(5), 773-83. https://doi.org/10.1080/09585190210125912

Foucault, M. (1978). The history of sexuality. New York: Pantheon Books.

Foucault, M. (2000). The subject and power. In J. D. Faubion (Ed.), Essential works of Foucault (1954-1984) (pp. 326-348). New York: The New Press.

Gallagher, C. (2000). White like me? Methods, meaning, and manipulation in the field of white studies. In F. Winddance-Twine, \& J. Warren (Eds.), Racing research, researching race: methodological dilemmas in critical race studies (pp. 67-92). New York: NYU Press.

Gannon, S., \& Davies, B. (2014). Postmodern, post-structural, and critical theories. In S. Hesse-Biber (Ed.), Handbook of feminist research: theory and praxis (pp. 65-91). Thousand Oaks: SAGE Publications.

Gautier, A. (2002). 10 Top women talk about their lives and their careers. New Zealand Management, 49(8), 32-36. Retrieved from http://web.a.ebscohost.com.helicon.vuw.ac.nz/ehost/pdfviewer/pdfviewer?vid=0\&sid =bc091d7f-8ad7-4208-9834-1c6fa5667367\%40sessionmgr4008

Gavey, N. (2012). Beyond "empowerment"? Sexuality in a sexist world. Sex Roles, 66(11), 719-723. https://doi.org/10.1007/s11199-011-0069-3 
Grbich, C. (2011). New approaches in social research. London: SAGE Publications Ltd.

Guillaumin, C. (1985). The masculine: denotations/connotations. Feminist Issues, 5(1), 6573. https://doi.org/10.1007/BF02685573

Headlam-Wells, J., Craig, J., \& Gosland, J. (2006). Encounters in Social Cyberspace: ementoring for professional women. Women in Management Review, 21(6), 483-499. https://doi.org/10.1108/09649420610683471

Headlam-Wells, J., Gosland, J., \& Craig, J. (2005). "There's magic in the web": e-mentoring for women's career development. Career Development International, 10(6/7), 444459. https://doi.org/10.1108/13620430510620548

Hearn, J. (2000). On the complexity of feminist intervention in organizations. Organization, 7(4), 609-624. https://doi.org/10.117/135050840074006

Hearn, J., \& Parkin, P. W. (2007). The emotionality of organization violations: gender relations in practice. In R. Simpson, \& P. Lewis, (Eds.) Gendering emotions in organizations (pp. 161-182). New York: Palgrave.

Hearn, J., Jyrkinen, M., Piekkari, R., \& Oinonen, E. (2008). Women home and away: transnational managerial work and gender relations. The Journal of Business Ethics, 83(1), 41-54. https://doi.org/10.1007/s10551-007-9655-2

Heilman, M. E., Block, C. J., Martell, R. F., \& Simon, M. C. (1989). Has anything changed? current characterisations of men, women and managers. Journal of Applied Psychology, 74(89), 935-942. Retrieved from https://search-proquestcom.helicon.vuw.ac.nz/docview/57563229?accountid=14782

Hesse-Biber, S. (2010). Qualitative approaches to mixed methods practice. Qualitative Inquiry, 16(6), 455-468. https://doi.org/10.1177/1077800410364611

Hesse-Biber, S., \& Leavy, L. (2007). Feminist research practice: an invitation to feminist research. Melbourne, Australia: Sage.

Hesse-Biber, S., \& Piatelli, D. (2014). The feminist practice of holistic reflexivity. In S. Hesse-Biber (Ed.), Handbook offeminist research: theory and praxis (pp. 557-582). Thousand Oaks: SAGE Publications, Inc.

Hoel, H., \& Einarsen, S. (2003). Violence at work in catering, hotels, and toursim. Geneva: International Labour Office. Retrieved from http://www.ilo.org/public/libdoc/ilo/2003/103B09_314_engl.pdf

Hoffman, C., \& Hurst, N. (1990). Gender stereotypes: perception or rationalisation? Journal of Personality and Social Psychology, 58(2), 197-208. https://doi.org/10.1037/00223514.58.2.197

Hofstede, G. (1991). Cultures and organizations: software of the mind (pp. 24- 54). London: McGraw-Hill.

Howe, K. R. (2004). A critique of experimentalism. Qualitative Enquiry, 10(1), 42-61. https://doi.org/10.1177/1077800403259491 
Intemann, K. (2016). Feminist standpoint. In L. Disch, \& M. Hawkesworth (Eds.), The Oxford handbook of feminist theory (pp. 1-23). Oxford: Oxford University Press.

Jack, B. (2010). Giving them a voice: the value of qualitative research. Nurse Researcher, 17(3), 4-7. Retrieved from https://link-galecom.helicon.vuw.ac.nz/apps/doc/A225791526/AONE?u=vuw\&sid=AONE\&xid=8ff4 $3 \mathrm{dc} 6$.

Kantola, J. (2008). "Why do all the women disappear?" Gendering processes in a political science department. Gender, Work and Organization, 15(2), 202-225. https://doi.org/10.1111/j.1468-0432.2007.00376.x

Kincheloe, J., \& McLaren, P. (2005). Rethinking critical theory and qualitative research. In N. K. Denzin, \& Y. Lincoln (Eds.), The landscape of qualitative research (pp. 303342). Thousand Oaks: CA: Sage.

King, N. (2004). Using templates in the thematic analysis of text. In C. Cassell, \& G. Symon (Eds.), Essential guide to qualitative methods in organizational research (pp. 257270). London: UK: Sage.

Knights, D., \& Kerfoot, D. (2004). Between representations and subjectivity: gender binaries and politics of organizational transformation. Gender, Work \& Organization, 11(4), 430-454. https://doi.org/10.1111/j.1468-0432.2004.00241.x

Knutson, B. A., \& Schmidgall, R. S. (1999). Dimensions of the glass ceiling in the hospitality industry. Cornell Hotel \& Restaurant Administration Quarterly, 40(6), 64-65. https://doi.org/10.1177/001088049904000618

Lacher, R. G., \& Oh, C. O. (2012). Is tourism a low-income industry? Evidence from three coastal regions. Journal of Travel Research, 51(4), 464-472. https://doi.org/10.1177/0047287511426342

Larner, W. (2003). Neoliberalism? Environment and Planning D: Society and Space, 21(5), 509-512. https://doi.org/10.1068/d2105ed

Lather, P. (2007). Getting lost: feminist efforts toward a double(d) science. New York: State University of New York Press.

Leck, J., Elliott, C., \& Rockwell, B. (2012). E-mentoring women: lessons learned from a pilot program. Journal of Diversity Management, 7(2), 83-96. https://doi.org/10.19030/jdm.v7i2.7476

Leckenby, D. (2007). Feminist empiricism: challenging gender bias and setting the record straight. In S. Hesse-Biber, \& P. Leavy (Eds.), Feminist research practice: a primer (pp. 27-52). Thousand Oaks: CA: Sage.

Lee, C. J. (2012). Reconsidering constructivism in qualitative research. Educational Philosophy and Theory, 44(4), 403-412. https://doi.org/10.1111/j.1469-

5812.2010.00720.x 
Lincoln, Y. S., \& Denzin, N. K. (2003). The seventh moment: Out of the past. In N. K. Denzin, \& Y. S. Lincoln, The landscape of qualitative research (pp. 611-640). Thousand Oaks: CA: Sage.

Lincoln, Y. S., \& Guba, E. G. (1985). Naturalistic inquiry. Newbury Park, CA: Sage.

Lueptow, L. B., Garovich-Szabo, L., \& Lupetow, M. B. (2001). Social change and the persistence of sex typing. Social Forces, 80(1), 1-36. https://doi.org/10.1353/sof.2001.0077

Marcinkus, W. C., Whelan-Berry, K. S., \& Gordon, J. R. (2007). The relationship of social support to the work-family balance and work outcomes of midlife women. Women in Management Review, 20(2), 86-111. https://doi.org/10.1108/09649420710732060

Maxwell, G. A. (1997). Hotel general management: views from above the glass ceiling. International Journal of Contemporary Hospitality Management, 9(5/6), 230-235. https://doi.org/10.1108/09596119710172624

Merriam-Webster. (2021). Merriam-Webster Dictionary. Retrieved from Merriam-Webster Dictionary: https://www.merriam-webster.com/dictionary

McIntosh, B., McQuaid, R., Munro, A., \& Dabir-Alai, P. (2012). Motherhood and its impact on career progression. Gender Management Review, 27(5), 981-989. https://doi.org/10.1108/17542411211252651

Meyerson, D. E., \& Fletcher, J. K. (2000). A modest manifesto for shattering the glass ceiling. Harvard Business Review, 78(1), 127-136. Retrieved from http://web.b.ebscohost.com.helicon.vuw.ac.nz/ehost/pdfviewer/pdfviewer?vid=0\&sid $=6154 \mathrm{~d} 627-9598-4$ af5-9e6d-bd62486316f7\%40sessionmgr101

Ministry of Business, New Zealand. (2020, February 12). Key Tourism Statistics. Retrieved from New Zealand Government: Ministry of Business, Innovation and Employment: mbie.govt.nz/dmsdocument/3438-key-tourism-statistics-pdf

Ministry of Health, New Zealand. (2020, June 13). COVID-19 current cases. Retrieved from Ministry of Health: Manatu Hauora: https://www.health.govt.nz/our-work/diseasesand-conditions/covid-19-novel-coronavirus/covid-19-current-situation/covid-19current-cases\#summary

Mooney, S., \& Ryan, I. (2009). A woman's place in hotel management: upstairs or downstairs? Gender in Management: An International Journal, 24(3), 195-210. https://doi.org/10.1108/17542410910950877

Mulvey, L. (1975). Visual pleasure and narrative cinema. Screen, 16(3), 6-18. https://doi.org/10.1093/screen/16.3.6

Nelson, J. A. (2014). The power of stereotyping and confirmation bias to overwhelm accurate assessment: the case of economics, gender and risk adversion. Journal of Economic Methodology, 21(3),211-230. https://doi.org/10.1080/1350178X.2014.939691

Ng, C. W., \& Pine, R. (2003). Women and men in hotel management in Hong Kong: perceptions of gender and career development issues. International Journal of 
Hospitality Management, 22(1),85-102. https://doi.org/10.1016/S02784319(02)00077-4

Nowell, L., Norris, J., White, D., \& Moules, N. (2017). Thematic analysis: striving to meet the trustworthiness criteria. International Journal of Qualitative Methods, 5, 1-13. https://doi.org/10.1177/1609406917733847

Noy, C. (2008). Sampling knowledge: the hermeneutics of snowball sampling in qualitative research. International Journal of Social Research Methodology, 11(4), 327-344. https://doi.org/10.1080/13645570701401305

Oakley, J. (2000). Gender-based barriers to senior management positions: understanding the scarcity of female CEOs. Journal of Business Ethics, 27(4), 321-334. Retrieved from https.//www.jstor.org/stable/25074386

Perez, S., Figueroa-Domecq, C., Fuentes-Moraleda, L., \& Munoz-Mazon, A. (2019). Incorporating a gender approach in the hospitality industry: female executives' perceptions. International Journal of Hospitality Management, 76, 184-193. https://10.1016/j.ijhm.2018.05.008

Pizam, A. (2017). The double bind phenomenon of hospitality female leaders. International Journal of Hospitality Management, 60, 142-143. https://doi.org/10.1016/j.ijhm.2016.11.007

Pleasants, R. (2011). Men learning feminism: protecting privileges through discourses of resistance. Men and Masculinities 14(2), 230-250. https://doi.org/10.1177/1097184X11407048

Poulston, J. (2008a). "Metamorphosis in hospitality: a tradition of sexual harrassment". International Journal of Hospitality Management 27(2), 232-240. https://doi.org/10.1016/j.ijhm.2007.07.013

Purcell, K. (1997). Women's employment in UK tourism. In M. T. Sinclear (Ed.), Gender, work and tourism (pp. 244-255). London: Routledge.

Raabe, B., \& Beehr, T. A. (2003). Formal mentorinig versus supervisor and coworker relationship: differences in perception and impact. Journal of Organizational Behaviour, 24(3), 271-293. https://doi.org/10.1002/job.193

Ragins, B. R., Townsend, B., \& Mattis, M. (1998). Gender gap in the executive suite: CEOs and female executives report on breaking the glass ceiling. The Academy of Management Executive, 12(1), 28-42. https://doi.org/10.5465/ame.1998.254976

RANZ, \& Statistics NZ. (2020). 2019 Hospitality Report. Auckland: Restaurant Association New Zealand.

Regine, B., \& Lewin, R. (2003). Third possibility leaders: the invisible edge women have in complex organisations. The Learning Organisation, 6(1), 347-352. https://doi.org/10.1108/09696470310497186

Salmons, J. (2016). Doing Qualitative Research Online. London: SAGE Publications Ltd. 
Service IQ, New Zealand. (2020, March 19). Wellington Service Sector Infographic. Retrieved from Service IQ: https://www.serviceiq.org.nz/assets/Attachments/WorkforceDevelopment/Wellington-Service-Sector-Infographic-August-2020.pdf

Shaw, R., Dyson, P., \& Peel, E. (2008). Qualitative psychology at M level: a dialogue between learner and teacher. Qualitative Research in Psychology, 5(3),179-191. https://doi.org/10.1080/14780880802314353

Smyth, R. (2012). NVivo (software). In L. Given (Ed.), The SAGE encyclopedia of qualitative research methods (pp. 564-565). Thousand Oaks: SAGE Publications, Inc.

Soufi, M., Gilaninia, S., \& Mousavian, S. J. (2011). Examine the relationship between selfesteem of women and lack of their appointment to organization senior posts. International Journal of Business and Social Science, 2(19), 287-292. Retrieved from http://www.ijbssnet.com/journals/Vol_2_No_19_Special_Issue_October_2011/35.pdf

Stanely, S. (1990). Recovering women in history from feminist deconstructionism. Women's Studies International Forum, 13, 151-157. https://doi.org/10.1016/02775395(90)90081-8

Statistics New Zealand. (2020, August 5). Underutilisation rate. Retrieved from Statstics New Zealand: https://www.stats.govt.nz/indicators/underutilisation-rate.

Stelter, N. (2002). Gender differences in leadership: current social issues and future organisational implications. The Journal of Leadership Studies, 8(4), 89-98. https.//doi.org/10.1177/107179190200800408

Townsend, B. (1997). Breaking through: the glass ceiling revisited. Equal Opportunities International, 16(5), 4-12. https://doi.org/10.1108/eb010692

Turban, D. B., Dougherty, T. W., \& Lee, F. K. (2002). Gender, race and percieved similarity effects in developmental relationships: the moderating role of relationship duration. Journal of Vocational Behavior, 61(2), 240-262. https://10.1006/jvbe.2001.1855

Visweswaran, K. (1994). Fictions of feminist ethnography. Minnesota: University of Minnesota Press.

Wahl, A. (1992). Gender structures in organisations: the career development of female graduate economists and engineers. Stockholm: Lund: Studentlitteratur.

Wahl, A. (2011). Men and women of the corporation. In R. M. Kanter, T. Jensen, \& L. Wilson (Eds.), On the shoulders of giants (pp. 187-202). Lund, Sweden: Studentlitteratur.

Wahl, A. (2012). Re-considering complicit masculinity. In J. Hearn, \& A. Biricik (Eds.), Gendered sexualised transnationalisations, deconstructing the dominant: transforming men, "centres" and knowledge/policy/practice (pp. 79-86). Linkoping: Linkoping University. 
Wahl, A. (2014). Male managers challenging and reinforcing the male norm in management. Nordic Journal of Feminist and Gender Research, 22(2),131-146. https://doi.org/10.1080/08038740.2013.864702

Waudby, B., \& Poulston, J. (2017). Sexualisation and harrassment in hospitality workplaces: who is responsible? International Journal of Culture, Tourism and Hospitality Research, 11(4), 483-499. https://doi.org/10.1108/IJCTHR-10-2016-0102

Weisman, C. B. (2017). Does feminism convince us: a response to "the case for feminist standpoint epistemology in social work research". Research on Social Work Practice, 27(4), 512-514. https://doi.org/10.1177/1049731516668037

West, C., \& Zimmerman, D. (1987). "Doing gender". Gender and Society, 1(2), 125-151. https://doi.org/10.1177/0891243287001002002

Weyer, B. (2007). Twenty years later: explaining the persistence of the glass ceiling and women leaders. Women in Management Review, 22(6), 482-496. https://doi.org/10.1108/09649420710778718

Wijesinghe, G. (2017). "Hostage to hospitality: is there a relationship between 'sexual hospitality' and sex in commerical hospitality?". Hospitality and Society, 7(2), 181201. https://doi.org/10.1386/hosp.7.2.181_1

Woodley, X. M., \& Lockard, M. (2016). Womanism and snowball sampling: Engaging marginalized populations in holistic research. The Qualitative Report, 21(2), 321-329. Retrieved from https://search-proquestcom.helicon.vuw.ac.nz/docview/1776156053?rfr_id=info\%3Axri\%2Fsid\%3Aprimo

Yea, S. (2005). Labour of love: Filipina entertainer's narratives of romance and relationships with GIs in US military camp towns in Korea. Women's Studies International Forum, 28(6), 456-472. https://doi.org/10.1016/j.wsif.2005.09.004 


\title{
Appendices
}

\author{
Appendix A: Interview Consent Form
}

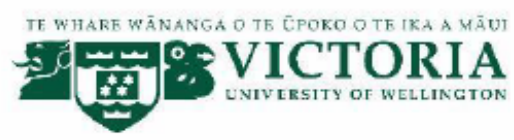

\section{Barriers to career development for women in hospitality \\ CONSENT TO INTERVIEW}

This consent form will be held for a minimum of 5 years.

Researcher: Leah Macpherson, School of Education, Victoria University of Wellington.

- I have read the Information Sheet and the project has been explained to me. My questions have been answered to my satisfaction. I understand that I can ask further questions at any time.

- I agree to take part in an audio recorded interview.

I understand that:

- I may withdraw from this study at any point before $1^{\text {st }}$ August 2019 and any information that I have provided will be returned to me or destroyed.

- $\quad$ The identifiable information I have provided will be destroyed on $3^{\text {rd }}$ March 2020.

- Any information I provide will be kept confidential to the researcher and the supervisor.

- I understand that the findings may be used for a Masters thesis.

- I understand that the recording will be kept confidential to the researcher and the supervisor.

- $\quad$ My name will not be used in reports and utmost care will be taken not to disclose any information that would identify me.

- I would like a copy of the transcript of my interview:

Yes $\square$ No

- I would like a summary of my interview:

Yes $\square$ No

- I would like to receive a copy of the final report and have added my email Ye address below.

Signature of participant:

Name of participant:

Date: 
Appendix B: Facebook Recruitment Post

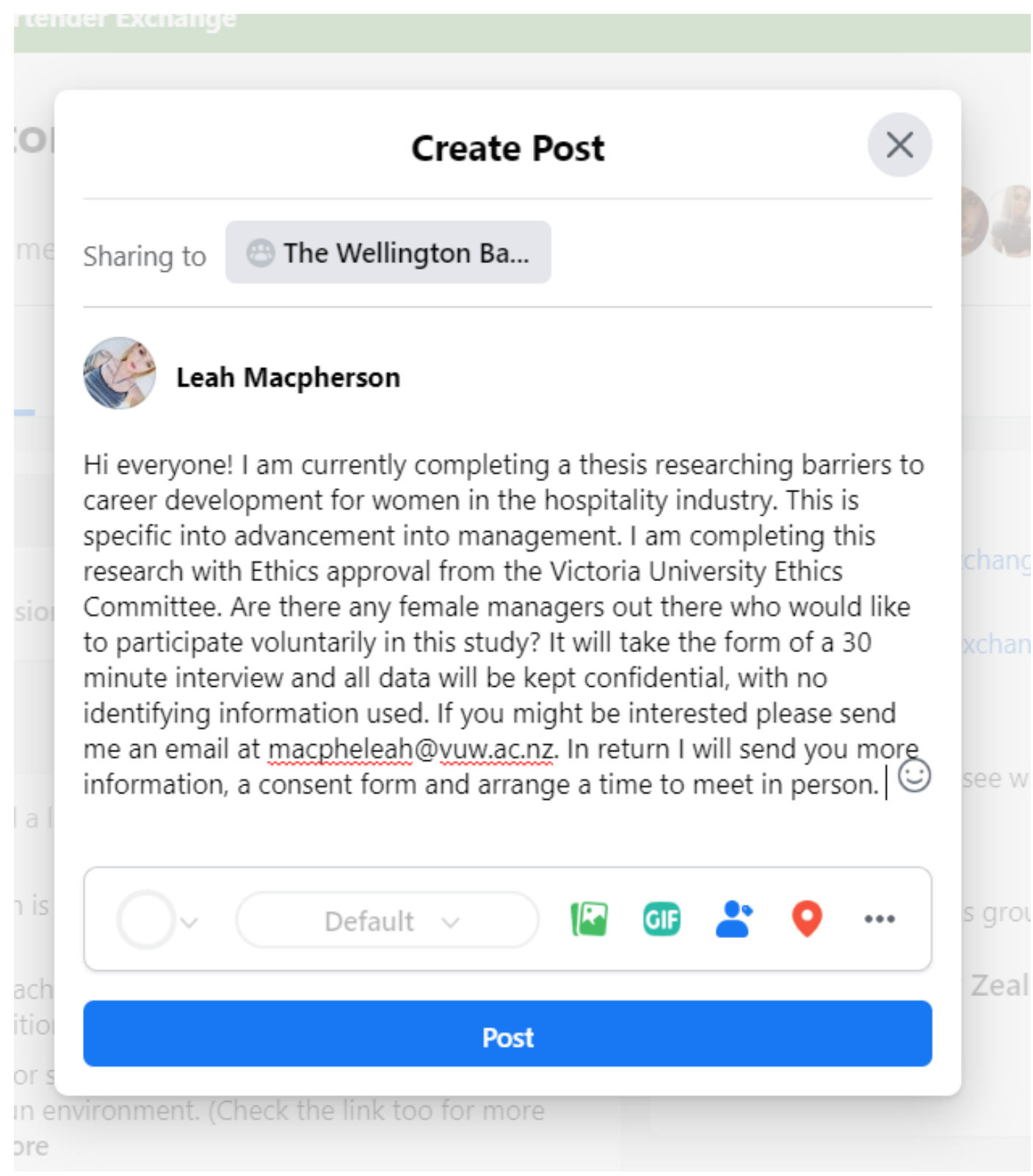


Appendix C: Information Sheet for Participants

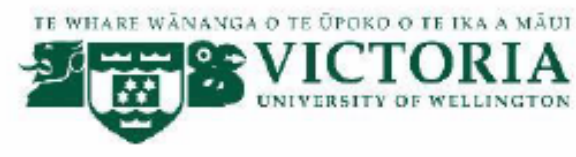

\section{Barriers to career development for women in hospitality}

\section{INFORMATION SHEET FOR INTERVIEW PARTICIPANTS}

You are invited to take part in this research. Please read this information before deciding whether or not to take part. If you decide to participate, thank you. If you decide not to participate, thank you for considering this request.

Who am I?

My name is Leah Macpherson and I am a master's student in Education at Victoria University of Wellington. This research project is work towards my thesis.

What is the aim of the project?

This project aims to understand the barriers women may face for promotions into upper management within the hospitality industry.

Your participation will support this research by speaking about your lived experiences as a manager, to contribute to the future of women in the industry. This research has been approved by the Victoria University of Wellington Human Ethics Committee \#0000027726.

\section{How can you help?}

You have been invited to participate because of your experiences employed as a manager within the New Zealand hospitality industry. If you agree to take part, I will interview you in a café of your choice, outside of your workplace. I will ask you questions about barriers you may have faced as a manager. The interview will take 30-40 minutes. I will audio record the interview with your permission and write it up later. You can choose to not answer any question or stop the interview at any time, without giving a reason. You can withdraw from the study by contacting me at any time before August $1^{\text {st }}, 2019$. If you withdraw, the information you provided will be destroyed or returned to you.

What will happen to the information you give?

This research is confidential. This means that the researcher named below will be aware of your identity but the research data will be combined and your identity will not be revealed in any reports, presentations, or public documentation.

Only my supervisor and I will read the notes or transcript of the interview. The interview transcripts, summaries and any recordings will be kept securely and destroyed on March $3^{\text {rd }}$, 2020. 
What will the project produce?

The information from my research will be used for my thesis in the completion of my master's in education degree.

If you accept this invitation, what are your rights as a research participant?

You do not have to accept this invitation if you don't want to. If you do decide to participate, you have the right to:

- choose not to answer any question;

- $\quad$ ask for the recorder to be turned off at any time during the interview;

- $\quad$ withdraw from the study before $1^{\text {st }}$ August 2019;

- ask any questions about the study at any time;

- receive a copy of your interview transcript;

- read over and comment on a written summary of your interview;

- be able to read any reports of this research by emailing the researcher to request a copy.

If you have any questions or problems, who can you contact?

If you have any questions, either now or in the future, please feel free to contact:

Student:

Name: Leah Macpherson

University email address:
Supervisor:

Name: Lex McDonald

Role: Senior Lecturer

School: Faculty of Education

Phone:

\section{Human Ethics Committee information}

If you have any concerns about the ethical conduct of the research you may contact the Victoria University HEC Convenor: Dr Judith Loveridge. 


\section{Appendices D: Interview Questions}

\section{INTERVIEW STRUCTURE:}

Ethical considerations: participants will give written consent for the interviews to be recorded, understand their rights as a voluntary participant and the procedure of the study, and that they will remain confidential.

Introduction: Interviews will begin with questions about the demographics related to the individual, age, nature of their hospitality business, and years of experience as a manager

Proceedings: Interview will proceed following guided questions, with elaborative answers prompted by the researcher. These are as follows:

- How would you describe your working experience as a female manager in the industry?

- How would you define your leadership style, and what are your key values as a manager? (Individualism vs. collectivism, competitiveness vs. collaboration)

- What was the process you undertook to get into a position of management? (experience, formalised certifications, mentorship, training)

- Were there any significant barriers you faced to becoming a manager? Were there also any enhancers? (sexism, individual notions of responsibility, cultural values)

- Can you identify any training/learning barriers that may have impeded your ability to further your career?

- Did you have a mentor that guided your leadership skills? If so, were they male or female? What were the benefits and/or detriments of this relationship?

- What do you think the industry could do differently to provide a better passage for potential female leaders?

- In gaining a certification, do you think that formal authorities (police, city council, health officers and hospitality New Zealand) provide adequate learning/training facilities? How could they be improved for potential female managers?

- Is there any follow up review from these formal institutions to sustain/solidify your learning or abilities?

- Can you identify any informal 'beliefs' or values surrounding your employability in the industry that you may have struggled with or experienced?

Conclusion: the interview will then conclude with an opportunity for the participant to comment further on any relevant details that may not have been discussed. 


\section{Appendices E: NVivo Coding Software: Coding Process}

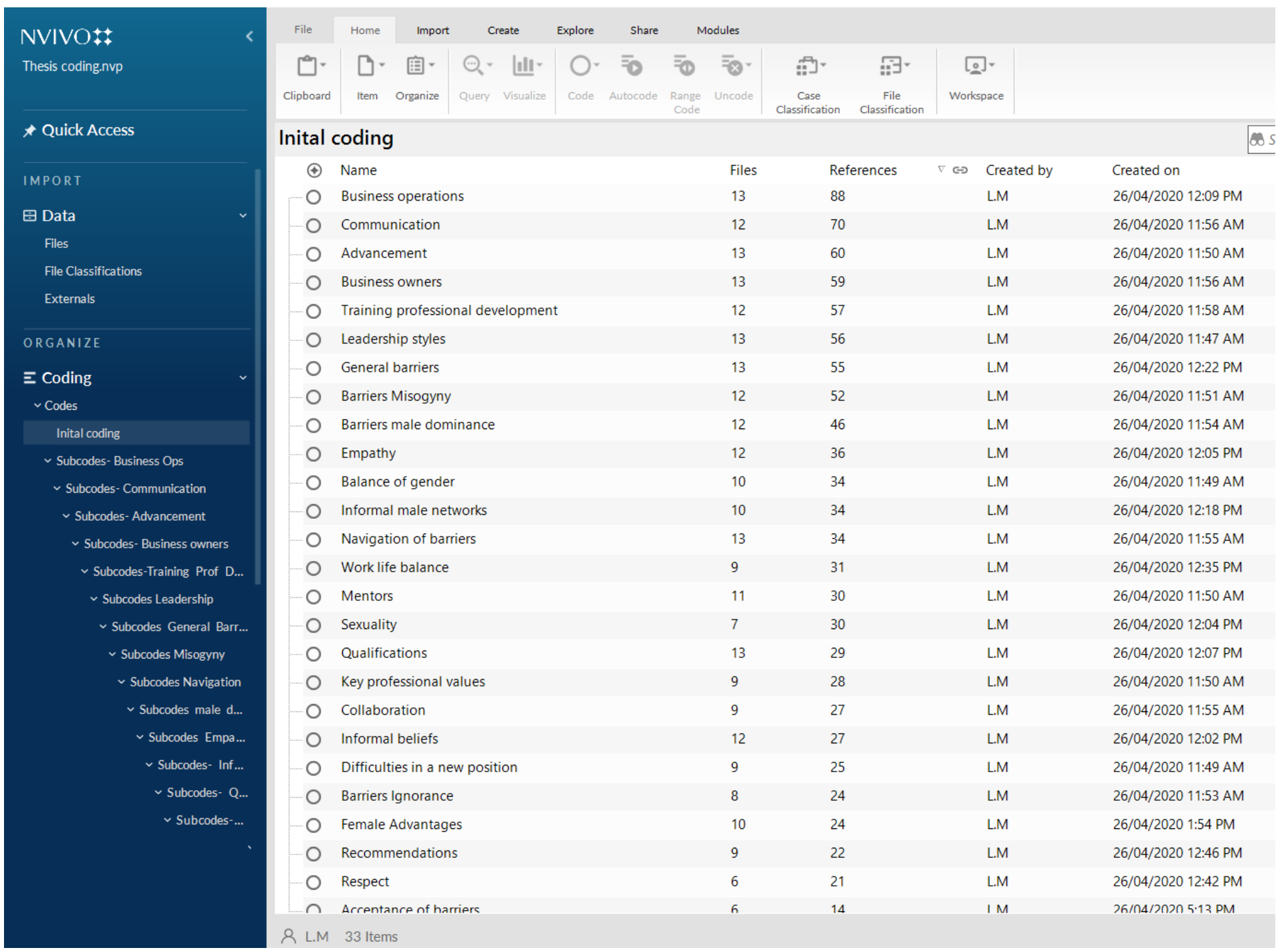

